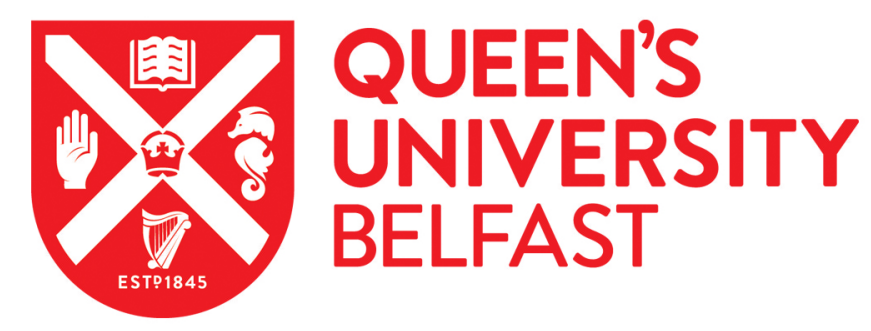

\title{
Cutting force and chatter stability analysis for PKM-based helical milling operation
}

Shi, M., Qin, X., Li, H., Shang, S., Jin, Y., \& Huang, T. (2020). Cutting force and chatter stability analysis for PKM-based helical milling operation. The International Journal of Advanced Manufacturing Technology , 111, 3207-3224 . https://doi.org/10.1007/s00170-020-06252-3

\section{Published in:}

The International Journal of Advanced Manufacturing Technology

\section{Document Version:}

Peer reviewed version

Queen's University Belfast - Research Portal:

Link to publication record in Queen's University Belfast Research Portal

\section{Publisher rights}

(C) 2020 Springer Nature

This work is made available online in accordance with the publisher's policies. Please refer to any applicable terms of use of the publisher.

\section{General rights}

Copyright for the publications made accessible via the Queen's University Belfast Research Portal is retained by the author(s) and / or other copyright owners and it is a condition of accessing these publications that users recognise and abide by the legal requirements associated with these rights.

Take down policy

The Research Portal is Queen's institutional repository that provides access to Queen's research output. Every effort has been made to ensure that content in the Research Portal does not infringe any person's rights, or applicable UK laws. If you discover content in the Research Portal that you believe breaches copyright or violates any law, please contact openaccess@qub.ac.uk. 
Title Page

Cutting force and chatter stability analysis for PKM-based helical milling operation

Mengrui Shi ${ }^{\mathrm{a}}$, Xuda Qin ${ }^{\mathrm{a}}$, Hao Li*,a, Shuai Shang ${ }^{\mathrm{a}}$, Yan Jin ${ }^{\mathrm{b}}$, Tian Huang ${ }^{\mathrm{a}, \mathrm{c}}$

${ }^{\text {a }}$ Key Laboratory of Mechanism Theory and Equipment Design of Ministry of Education, Tianjin University, Tianjin 300072, China

${ }^{\mathrm{b}}$ School of Mechanical and Aerospace Engineering, Queens University, Belfast, BT5 9AH, UK

${ }^{c}$ School of Engineering, University of Warwick, Coventry, CV4 7AL, UK

Corresponding author: Hao $\mathrm{Li}$

Email: haolitju@tju.edu.cn

Mengrui Shi Email: shimengrui@tju.edu.cn

Xuda Qin Email: qxd@tju.edu.cn

Hao Li Email: haolitju@tju.edu.cn

Shuai Shang Email:shangshuai@tju.edu.cn

Yan Jin Email: y.jin@qub.ac.uk

Tian Huang Email: tianhuang@tju.edu.cn 


\title{
Cutting force and chatter stability analysis for PKM-based helical milling operation
}

\author{
Mengrui Shi ${ }^{\mathrm{a}}$, Xuda Qina ${ }^{\mathrm{a}}$ Hao Li ${ }^{*, a}$, Shuai Shang ${ }^{\mathrm{a}}$, Yan Jin ${ }^{\mathrm{b}}$, Tian Huang ${ }^{\mathrm{a}, \mathrm{c}}$ \\ ${ }^{\text {a }}$ Key Laboratory of Mechanism Theory and Equipment Design of Ministry of Education, Tianjin \\ University, Tianjin 300072, China \\ ${ }^{\mathrm{b}}$ School of Mechanical and Aerospace Engineering, Queens University, Belfast, BT5 9AH, UK \\ c School of Engineering, University of Warwick, Coventry, CV4 7AL, UK
}

\begin{abstract}
In order to enhance the manufacturing productivity, mobile machining with industrial robots is proposed as a cost-effective and portable manufacturing alternative to large scale CNC machine tools in aircraft part machining. Combing the advantages of helical milling and parallel robot, the cutting forces and chatter stability of a novel 5-DOF hybrid PKM (named TriMule) based helical milling process are first investigated in this paper. The cutting force and dynamic model of PKM based helical milling operation are proposed, and the chatter stability diagrams at the seven representative machining positions are obtained based on the Complete Discretization Scheme with Euler's method approach. The predicted cutting forces and chatter stability diagrams are experimentally validated by the PKM based titanium alloy helical milling. It can be found that the PKM machining position has a great influence on the corresponding limit stable axial depth of cut in the helical milling operation. Meanwhile, it was indicated that the spindle speed is an important factor affecting the helical milling stability difference at different machining positions. Meanwhile, it was found that the helical milling stability is only determined by $2 \mathrm{nd}, 3 \mathrm{rd}$ and 4 th order modes of TriMule when the spindle speed is higher than $1000 \mathrm{rpm}$ with the first 4 mode of the cutting system considered. The research results are expected to provide a basis for the helical milling parameter optimization and reasonable robot machining position selection.
\end{abstract}

Key words: PKM; Helical milling; Cutting force; Complete-discretization method; Stability lobe diagram

\section{Nomenclature}

$F_{x}, F_{y}, F_{z} \quad$ cutting forces applied by the end-effector

$k_{x}, k_{y}, k_{z} \quad$ stiffness of PKM end-effector along the direction of cutting forces

$F_{p} \quad$ cutting force caused by the peripheral cutting edges

$F_{f} \quad$ cutting force caused by the front cutting edges

$h\left(\theta^{i}\right) \quad$ undeformed thickness of cutting chip of the tooth $i$

$d b \quad$ differential width of cut

$d S_{i} \quad$ differential edge length

$F_{a}, F_{r}, F_{t} \quad$ cutting forces in the directions of axial, radial and tangential

$K_{r c}, K_{t c}, K_{a c}$ cutting force coefficients associated with the thickness of cutting chips which are named shear effect coefficients for the radial, tangential and axial direction

$K_{r e}, K_{t e}, K_{a e}$ independent of the thickness of cutting chips which are named the friction (or plowing) effect coefficients for the radial, tangential and axial direction

$\theta^{i} \quad$ instantaneous immersion angle

$\theta_{P} \quad$ pith angle of the tool

$\varphi(z) \quad$ lag angle for a particular disk 


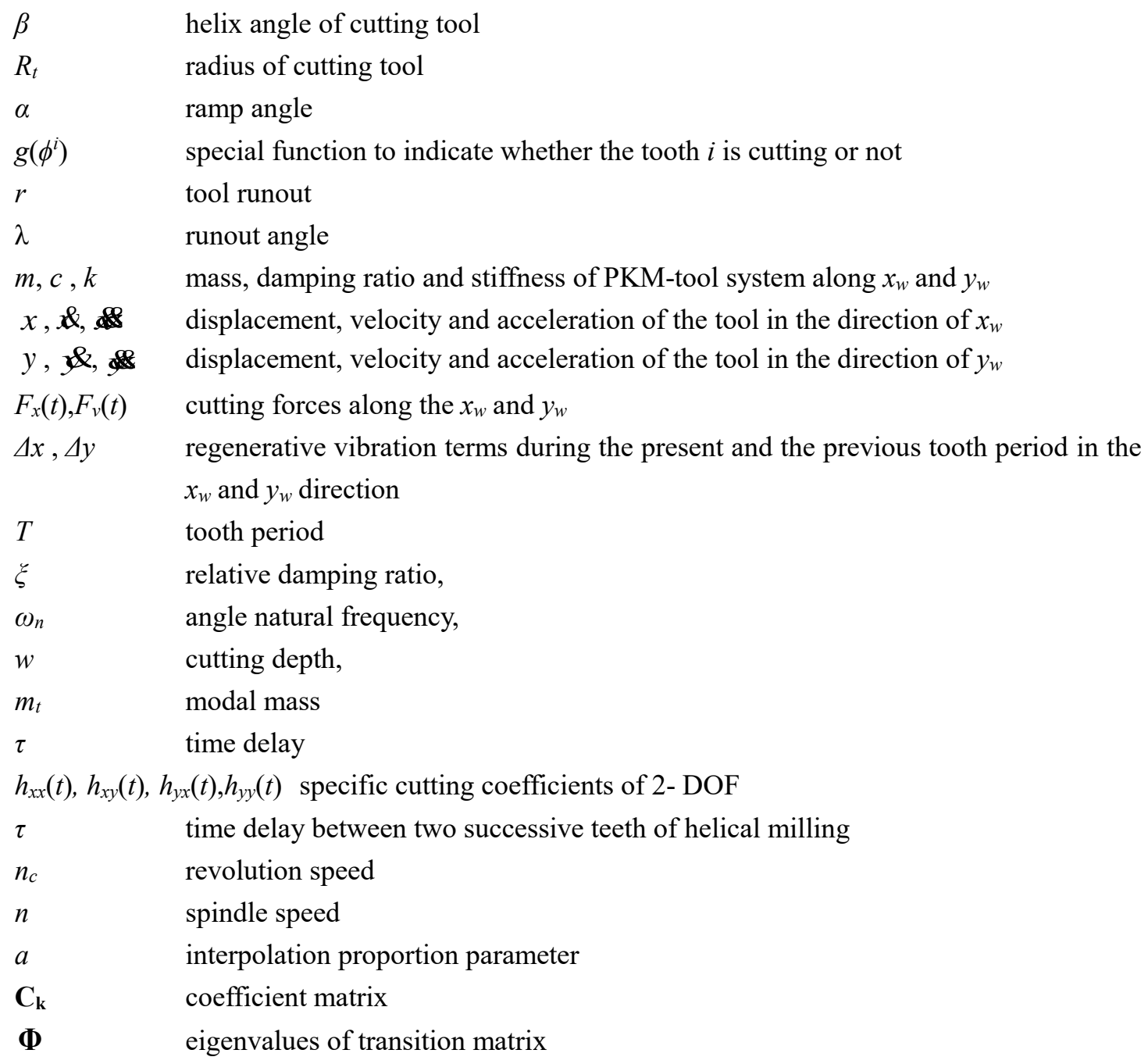

\section{Introduction}

Since the excellent mechanical properties, the titanium alloy is widely used in the aircraft manufacturing, such as aircraft central wing box, engine components, skin, skeleton, fasteners and landing gear et al. [1] However, due to the fact that titanium alloy is one of the hard-to-process materials, how to control its machining quality and accuracy has become a research hotspot in the aerospace manufacturing field. Here, the production of bolt/fixation holes is essential to the aircraft assemble process, which is also considered as the most time-consuming process [1-2]. Currently, the hole-making process in the aircraft assembly always involves a series drilling, reaming, disassembly, deburring and reassembly operations, and conventional drilling has its own drawbacks which include high axial cutting force, high cutting temperature during the hole making, poor dimensional and geometrical accuracy, poor surface quality, catastrophic tool wear and so on [3-5]. Thus, many approaches have been investigated to improve the hole quality, such as optimizing process parameters, tool material and coating, applying advanced cooling strategy, and adopting new hole-making methods [6-7]. For new hole-making methods, helical milling (also known as orbital drilling) has been investigated as an alternative to conventional drilling due to its significant advantages, such as lower cutting forces and temperature, flexible kinematics, and better borehole quality [8-10]. The previous publications mainly focused on the applicability of the operation and 
its potential to replace conventional drilling process, and in the recent work, the prediction of vibration, hole surface quality and chatter free spindle speed has also been involved. Li et al. [11] presented the study to predict the chatter stability diagram which including pitch length of cut versus spindle speed, and the impact of helical milling geometry on the stability in helical milling operation. Liu et al. [12] presented an analytical model to deal with the time domain cutting force prediction and time/frequency domain dynamics analysis for the helical milling process. Ozturk et al. [13] proposed a unified model of helical milling to predict the cutting force, chatter stability and hole surface error together, and a 3D stability chart is presented for the optimal selection helical milling parameters.

In order to enhance the manufacturing productivity, mobile machining with industrial robots is proposed as a cost-effective and portable manufacturing alternative to large scale CNC machine tools in large-scale part manufacturing, and lots of explorations about the robot-based hole-making were carried out by researchers recently. Shan et al. [14] built a vector model of helical milling operation and deduced the corresponding surface roughness prediction formula. Eguti et al. [3] designed a new helical milling end-effector for the industrial robot, and the achieved results show that the process requirements and tolerances are suitable for aeronautic application. Chen et al. [15] designed a new type of tool with multi-point front cutting edge for serial robot based helical milling which can increase the tool life and improve the machining quality. Cordes et al. [16] presented dynamics of serial robot end milling and obtained the stability charts using the semi-discrete time and frequency method, which are experimentally validated in milling of aluminum and titanium parts. Huynh et al. [17] built two multi-body dynamics models of articulated serial robots suitable for machining applications to predict the position-depending dynamics of KUKA KR90 R3100 Robotic Arm. Mousavi et al. [18] dealt with the optimization of serial robotic machining stability by controlling the robot configurations and the functional redundancies of its kinematic chain. The robotic manipulators used in above investigation provide high degrees of flexibility to enable manufacture parts with large or/and complex geometries. However, there are limitations to the serial robotic system as flexibility and accuracy are inversely correlated [19]. Due to their weak and varied stiffness along the hole axis direction, industrial serial robots are more suitable for low cutting force related machining process, but not for drilling/machining the hard-to-cut titanium alloy materials which is always accompanied with large cutting force [20]. Hence, another type of robots named parallel robots which are also called parallel kinematic machines (PKMs) are worthy to introduce [21]. PKMs are consisted of more than two links, which are interconnected with the base and the moving platform, so that the links would form closed chains and constrain the movement of each other [22]. Thus, according to the structure characteristics of PKMs, its stiffness is superior to the serial kinematic machines which made it appropriate for hard-to-process materials machining, such as titanium alloy and carbon fiber reinforced plastics [23]. Although the high stiffness and high precision of PKMs can largely reduce the machining damage and geometric errors comparing with conventional serial robots, the vibrations and stability of PKM based helical milling operation is also need to be further investigated for better hole quality.

As a new type of machining equipment, the machining stability is one of the most important indexes to evaluate its dynamic characteristics. Najafi et al. [24] investigated the effect of machine configuration on the machine stability for Hexaglide machine tool based on the simulation and experimental approach, and it was concluded that machine stability is dependent on the spindle/tool/ holder system characteristic. Pedrammehr et al. [25] studied the vibration of the Stewart platform- 
based machine tool table under different configurations and cutting conditions. Law et al. [26] proposed a reduced substructural finite element models of a hybrid serial-parallel machine, and the stability diagrams are simulated as a function of machine positions to identify the productivity levels within the machine work volume. Tunc et al. [27] investigated distinctive effects of Stewart platform-type of hexapod robot on stability of robotic milling based on the characterization of structural dynamics, simulation of stability limits and experimental validation. In summary, although numbers of articles have been published to study the stability of PKM based machining process, most of these papers only focused on the end milling, and there have been few studies focused on the cutting stability of PKM based helical milling process.

In this paper, the cutting forces and chatter stability of a novel 5-DOF hybrid PKM based helical milling process are first investigated. The paper structure is organized as follows. In the section 2, the robot stiffness is investigated to select the reasonable machining position range, and a PKM based helical milling prediction force model is proposed with considering the robot deformation. The dynamic model of PKM based helical milling and the prediction method of cutting stability with different machining position are conducted in section 3 . In section 4 , experiments are carried out to verify the proposed cutting force and cutting stability models, and the influence of the machining positions of the PKM on the cutting stability is also discussed in this section. The paper is finalized with conclusions and remarks in section 5.

\section{Cutting forces modelling of helical milling process}

\subsection{Stiffness analysis for the PKM}

The PKM used in these cutting coefficients identification is a novel 5-DOF hybrid PKM named TriMule which have been proposed by Tian et al. [28]. As shown in Fig. 1, the PKM is composed of a 3-DOF R(2-RPS\&RP)\&UPS parallel mechanism plus a A/C wrist. Here, R, P, U, and $S$ represent revolute, prismatic, universal, and spherical joints respectively; and $\mathrm{P}$ denotes an actuated prismatic joint. The parallel mechanism comprises a spatial limb plus a 2-RPS\&RP planar linkage, connected by a pair of $\mathrm{R}$ joint to the machine frame at either side of the base link which is elaborately designed into a three-in-one base link. The spindle is on the $\mathrm{A} / \mathrm{C}$ wrist which is used for different types of 5 axis lineage work. The basic technical parameters of TriMule are given in the Table 1.

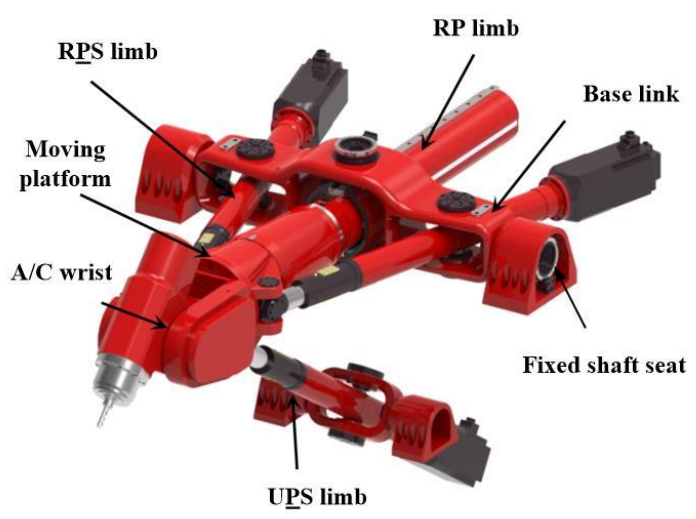

Figure.1 CAD model of TriMule hybrid PKM

The stiffness of the end-effector of hybrid PKM is one of the main reason effected the machining accuracy. Therefore, the stiffness of end-effector of TriMule was firstly calculated by 
simulation, and the stiffness distribution in the workspace was obtained in this paper. The workspace is optimized according to the stiffness distribution, which is used as the research scope of the subsequent cutting stability analysis of titanium alloy helical milling process.

Table 1 Technical parameters of TriMule robot

\begin{tabular}{c|c|c}
\hline \multirow{2}{*}{ Kinematic characteristics } & Maximum feedrate & $60 \mathrm{~m} / \mathrm{min}$ \\
\cline { 2 - 3 } & Maximum acceleration & $10 \mathrm{~m} / \mathrm{s}^{2}$ \\
\hline \multirow{2}{*}{ Precision } & Positional accuracy & $0.06 \mathrm{~mm}$ \\
\cline { 2 - 3 } & Repeatability accuracy & $0.02 \mathrm{~mm}$ \\
\hline Mass & \multicolumn{2}{|c}{$540 \mathrm{~kg}$} \\
\hline Control system & Turbo PMAC+IPC Solution Line \\
\hline \multirow{2}{*}{ Geometry } & Length & $2030 \mathrm{~mm}$ \\
\cline { 2 - 3 } & Width & $1250 \mathrm{~mm}$ \\
\hline \multirow{2}{*}{ Spindle } & Interface of cutting tool & HSK-E40 \\
\cline { 2 - 3 } & Maximum spindle speed & $36,000 \mathrm{rpm}$ \\
\cline { 2 - 3 } & Power & $7.5 \mathrm{KW}$ \\
\cline { 2 - 3 } & Torque & $6.1 \mathrm{Nm}$ \\
\hline
\end{tabular}

SAMCEF Field FEA software was used to simulate the stiffness of the TriMule hybrid PKM. The steps of the analysis simulation of SAMCEF software are: creating geometric models, input analysis data, meshing, simulation and result output. The specific content of each step is as follows:

(1) First, 3D models of each part and the whole PKM are created by Solidworks 3D modeling software. In order to reduce the calculation time, the models are simplified according to the simplification principle, which some detailed features such as holes, openings, small bosses and grooves, etc. in the parts are removed due to the less influence on the simulation result. Finally, each part is assembled together and the 3D model of the whole PKM is imported into SAMCEF through the data interface.

(2) The input of finite element parameters endowing the characteristics of each structure unit, material properties, boundary conditions, load conditions, etc., to determine the initial conditions of hybrid PKM simulation.

(3) Meshing is carried out after free mesh generation and mesh constraint conditions are set for the TriMule hybrid PKM.

(4) Calculation and results output.
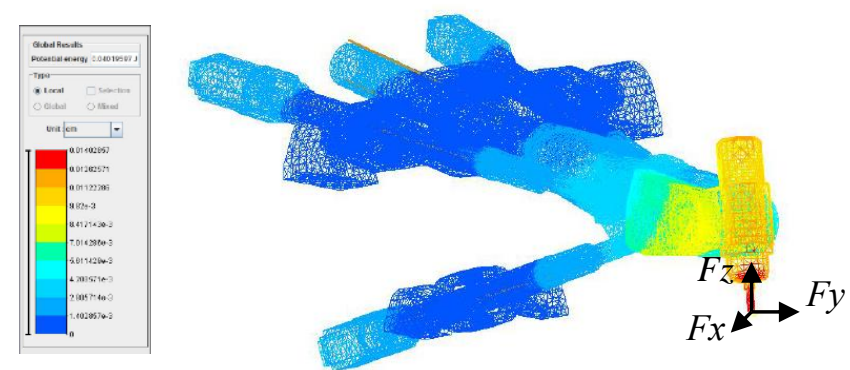

Fig. 2 Simulation results of TriMule robot deformation under cutting force load. $(\mathrm{Fx}=\mathrm{Fy}=250 \mathrm{~N}$, $\mathrm{Fz}=200 \mathrm{~N})$ 
The workspace size parameters of the TriMule hybrid PKM are shown in Figure 3. According to the limit position of the workspace (yellow area in the Fig.3), 73 simulation positions were selected to calculate the stiffness of end-effector of TriMule, and then the changing trend of the endeffector PKM stiffness in the overall workspace was fitted. The simulation results are shown in Figure 4. It can be seen from the Fig.4 that the stiffness of end-effector of TriMule hybrid PKM in the three directions is the largest in the middle position of the workspace, and tends to decrease in the border position. Secondly, the y-direction stiffness $k_{y}$ is obviously much greater than the $x$ and $z$-direction stiffness among the three directions. As the stiffness of the end-effector of TriMule directly affects the machining accuracy, this paper first selects a more reasonable workspace according to the simulation results of the stiffness of end-effector in the whole workspace to study the influence rule of different positions in the workspace on the stability of helical milling process. Furthermore, from the stiffness analysis results, it can be seen that the stiffness in different directions varies greatly and is much weaker than that of the machine tool. Therefore, the influence of mechanism deformation on instantaneous chip thickness should be considered in the subsequent cutting force modeling process.

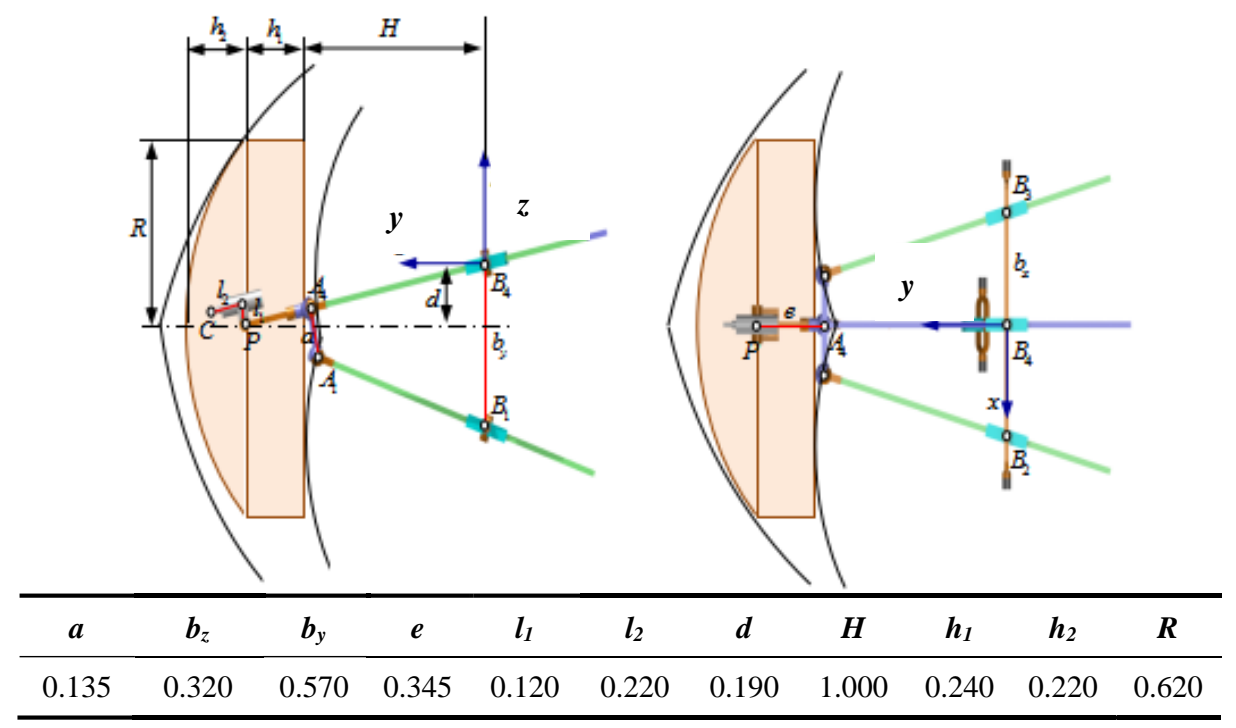

Fig. 3 TriMule robot workspace and dimensional parameters (in meters)
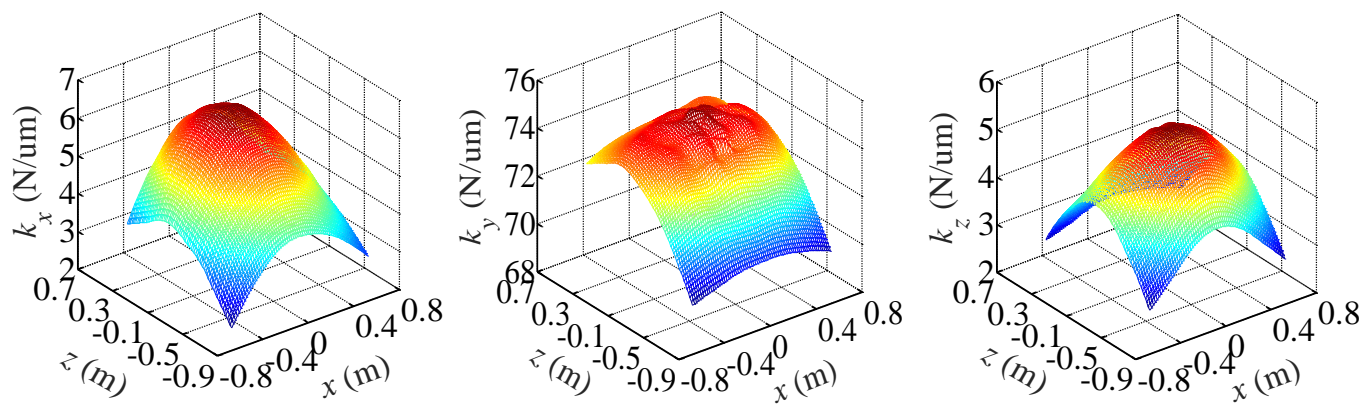

Fig. 4 The schematic diagram of robot end stiffness

\subsection{Helical milling cutting force model with consideration of TriMule robot deformation}

The model presented in this section incorporates the effect of robot end deflection on the force model in helical milling operation. Different from ordinary milling, helical milling hole-making 
process contains three independent movements, which are spindle rotation $n$, orbital rotation $n_{c}$, and axial feed $V_{c} . P$ is the position of the tip point of cutter. $\varphi$ is the rotation angle of cutting tooth located in $P$, as shown in Fig. 5. Therefore, The forces model for helical milling hole-making can be obtained by calculating the cutting forces generated by the peripheral cutting edges ( $F_{p}$, which is same with the peripheral milling) and front cutting edges ( $F_{f}$, which is like drilling process).

The forces model for the peripheral milling is based on a mechanistic approach which discretizes the cutting edge, obtains the forces on each differential element and integrates the forces to take into account the contribution to the total forces of each cutting edge in cut. The tangential, radial and axial cutting force components depend on the correspondent cutting coefficients, the chip thickness $h\left(\theta^{i}\right)$, the differential width of cut $d b$, and the differential edge length $d S_{i}$ :

$$
\left\{\begin{array}{l}
d F_{t, j}=K_{t c} h\left(\theta^{i}\right) d b+K_{t e} d S_{i} \\
d F_{r, j}=K_{r c} h\left(\theta^{i}\right) d b+K_{r e} d S_{i} \\
d F_{a, j}=K_{a c} h\left(\theta^{i}\right) d b+K_{a e} d S_{i}
\end{array}\right.
$$

(a)

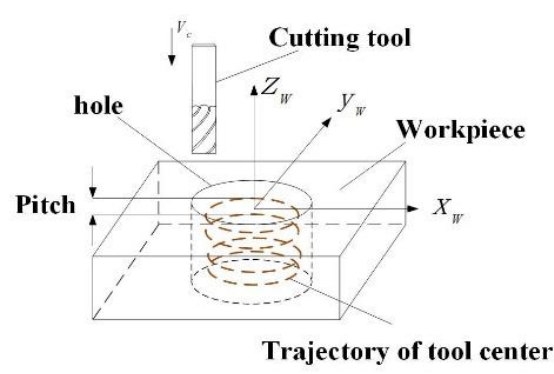

(b)

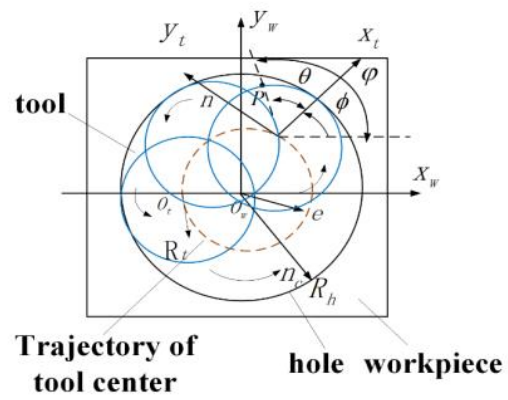

Figure. 5 Kinematics of helical milling, (a) tool-workpiece system (b) top view of helical milling processing

where $F_{a}, F_{r}$ and $F_{t}$ are the cutting forces in the directions of axial, radial and tangential respectively. $i$ is the number of the cutter teeth, $h\left(\theta^{i}\right)$ is the undeformed thickness of cutting chip of the tooth $i$. $K_{r c}, K_{t c}$ and $K_{a c}$ are the cutting force coefficients associated with the thickness of cutting chips which are named shear effect coefficients for the radial, tangential and axial direction respectively. The cutting force coefficients $K_{r e}, K_{t e}$ and $K_{a e}$ are independent of the thickness of cutting chips which are named the friction (or plowing) effect coefficients for the radial, tangential and axial direction respectively.

The differential width of cut $d b$ depends on the geometry of the tool as:

$$
d b=d z / \sin \kappa
$$

where $\kappa=90^{\circ}$ in this paper. The undeformed chip thickness at certain location on the cutting edges can be obtained by:

$$
h\left(\theta^{i}\right)=s_{t} \sin \left(\theta^{i}\right)
$$

The instantaneous immersion angle $\theta^{i}$ at axial elevation $\mathrm{z}$ is expressed as

$$
\theta^{i}=\theta_{1}^{i}+(i-1) \theta_{P}-\varphi(z)
$$

where $\theta_{P}=2 \pi / N$ is pith angle of the tool. The lag angle for a particular disk is given by $\varphi(z)=z \times \tan \beta / R_{t}$, where $\beta$ and $R_{t}$ are the helix angle and radius of cutting tool. The differential edge length can be 
obtained as:

$$
d S_{i}=d z \sqrt{\left(r(z) \varphi^{\prime}(z)\right)^{2}+\left(r^{\prime}(z)\right)^{2}+1}
$$

where $r(z)=R_{t}$. The tangential, radial and axial differential forces are projected over the Cartesian axes by means of a rotation matrix:

$$
\left\{d F_{x y z, i}\right\}=\left[\begin{array}{ccc}
\cos \alpha & 0 & 0 \\
0 & \cos \alpha & 0 \\
-\sin \alpha & -\sin \alpha & 1
\end{array}\right]\left[\begin{array}{ccc}
-\cos \theta^{i} & -\sin \kappa \sin \theta^{i} & -\cos \kappa \sin \theta^{i} \\
\sin \theta^{i} & -\sin \kappa \cos \theta^{i} & -\cos \kappa \cos \theta^{i} \\
0 & \cos \kappa & -\sin \kappa
\end{array}\right]\left\{d F_{t r a, i}\right\}
$$

where the ramp angle $\alpha=\arctan \left(a_{p} /\left(2 \pi \times\left(R_{h}-R_{t}\right)\right)\right)$. For the helical milling hole-making process [10], the final axial cutting force is a combination of two parts: the cutting force induced by peripheral and bottom edges. The axial cutting force induced by peripheral edges can be obtained by Eq. (1), and the axial cutting force caused by bottom cutting edges can be expressed as:

$$
F_{F a}=K_{F a c} R_{t} a_{t}+K_{F a e} R_{t}
$$

Thus, considering all the cutting teeth of cutting tool in helical milling processing, the resultant force of the cutting tool is:

$$
\left\{\begin{array}{l}
F_{x}=\sum_{i=1}^{N} g\left(\phi^{i}\right) \int_{z_{1}}^{z_{2}} d F_{x, i} \\
F_{y}=\sum_{i=1}^{N} g\left(\phi^{i}\right) \int_{z_{1}}^{z_{2}} d F_{y, i} \\
F_{z}=\sum_{i=1}^{N} g\left(\phi^{i}\right) \int_{z_{1}}^{z_{2}} d F_{z, i}+N\left[k_{F a c} R_{t} a_{t}+k_{F a e} R_{t}\right]
\end{array}\right.
$$

where $g\left(\phi^{i}\right)$ is a special function to indicate whether the tooth $i$ is cutting or not, which can be expressed by:

$$
g\left(\phi^{i}\right)=\left\{\begin{array}{l}
1, \text { tooth } i \text { is cutting } \\
0, \text { tooth } i \text { is not cutting }
\end{array}\right.
$$

In the cutting force analysis process, we assumed that the tool suffers only static deflections during the helical milling, and the stiffness of robot end is approximately the static one as well. Therefore, at each robot machining position, it can be supposed that the robot end/tool deforms to a certain deflection where there is a balance between the cutting forces and the elastic force at the robot end. Thus, by ignoring damping and inertia forces, the equation of tool motion can be expressed as:

$$
\left[\begin{array}{ll}
k_{x x} & k_{x y} \\
k_{y x} & k_{y y}
\end{array}\right]\left\{\begin{array}{l}
x(t) \\
y(t)
\end{array}\right\}=\left\{\begin{array}{l}
F_{x} \\
F_{y}
\end{array}\right\}
$$

As presented in Eq. (10), only the deflection in the $\mathrm{X}$ and $\mathrm{Y}$ plane were considered in this paper. From the Eq. (1), it can be concluded that cutting forces depend on the chip thickness, which is decided by displacements of tool/robot end and tool runout $r$ [29]:

$$
h^{\prime}\left(\theta^{i}\right)=\left(s_{t} \sin \theta^{i}+r \cos \lambda+\Delta x \sin \theta^{i}+\Delta y \cos \theta^{i}\right) \sin \kappa
$$

where $\lambda$ is the runout angle, $\Delta x$ and $\Delta y$ are the displacements take into account the deflection on the 
previous tooth engagement, where $\Delta x=x(t)-x(t-T)$, and $\Delta y=y(t)-y(t-T)$.

Hence, in order to obtain the cutting force with considering the robot deflection, the following iterative procedure has been programmed. First, the cutting force with rigid robot/tool hypothesis are calculated based on Eq. (8) for a given tool geometry and cutting parameter. The deflection caused by these forces can be obtained based on the simulation results of robot end stiffness. Hence, in a flexible cutting system, the above displacement will change the real chip thickness, and lead to the variation of cutting force. Considering the calculation cost and the error of cutting force, an error allowable value $e$ is set. In each calculation period, the cutting force $F$ subjected to the tool is first calculated, and then the cutting force $F^{\prime}$ under deformation is calculated based on the tool deflection caused by $F$, and finally the difference between $F^{\prime}$ and $F$ is judged to be less than $e$. If not, the cutting force $F^{\prime}$ continues to circulate until the error is less than $e$. The final output cutting force $F$ is the cutting force received by the tool. The above proposed procedure is shown in Fig. 6 .

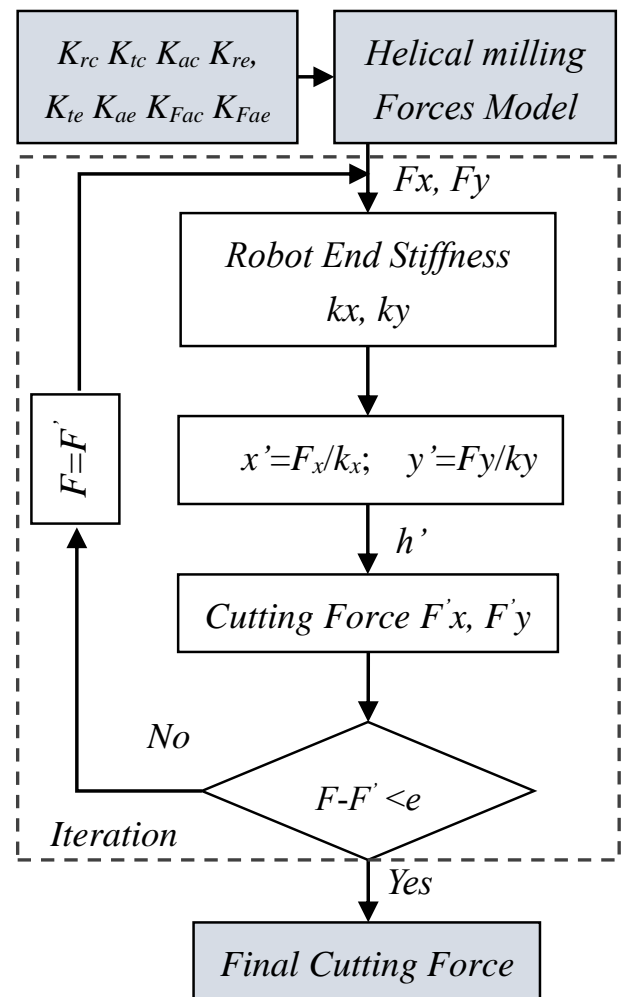

Fig. 6 Iterative procedure for the helical milling cutting force prediction with considering the robot deformation

\section{Dynamic analysis of PKM-based helical milling}

As mentioned above, the process of helical milling can be divided into two parts which are the drilling processing of bottom cutting edges and ordinary milling of side cutting edge respectively. Comparing with the horizontal direction, the vibration along the axial direction has little effect on the hole surface quality. Besides, the rigidity of PKM-tool-workpiece in axis direction is much higher. Therefore, in order to simplify the model, only the stability in $x_{w}$ and $y_{w}$ are considered in this paper, as shown in Fig. 7. Therefore, the differential equations of cutting dynamics of the PKMtool-workpiece system can be expressed as[30]: 


$$
\left\{\begin{array}{l}
m_{x} c_{x} \&+k_{x} x=F_{x}(t) \\
m_{y} c_{y} \&+k_{y} y=F_{y}(t)
\end{array}\right.
$$

where $m, c$ and $k$ are the mass, damping ratio and stiffness of PKM-tool system along $x_{w}$ and $y_{w}$ respectively. $x, \&$ and $y, \&$ are the displacement, velocity and acceleration of the tool in the direction of $x_{w}$ and $y_{w} . F_{x}(t)$ and $F_{y}(t)$ are the cutting forces along the $x_{w}$ and $y_{w}$ which have analyzed in the section 2 .

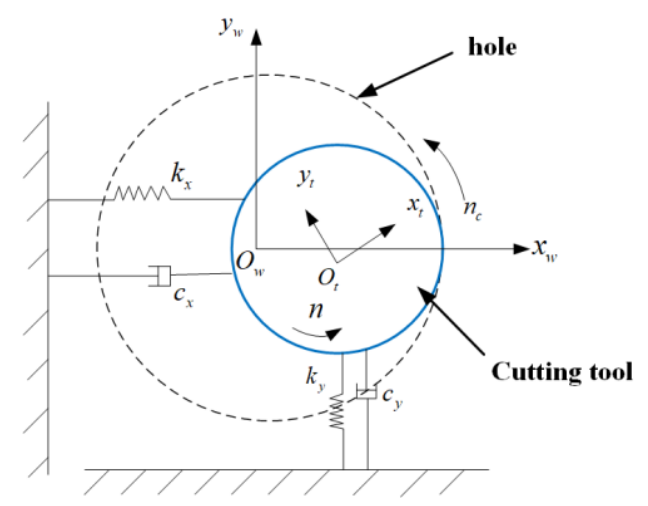

Figure 7. Simplified 2-DOF vibration dynamic model for helical milling process

In order to analyze the stability of milling process, regenerative chatter is worth to introduce which mainly result from the variation in the dynamic chip thickness shown in Fig.8. Therefore, according to Li et al. [31], the dynamic chip thickness of tooth $j$ in the coordinate $O_{w} x_{w} y_{w}$ can be expressed as:

$$
h_{d}\left(\theta^{i}\right)=s_{t} \sin \left(\theta^{i}\right)+\Delta x \sin \left(\varphi_{i}\right)+\Delta y \cos \left(\varphi_{i}\right)
$$

where $\Delta x$ and $\Delta y$ represent regenerative vibration terms during the present and the previous tooth period in the $x_{w}$ and $y_{w}$ direction which can be expressed as:

$$
\left\{\begin{array}{l}
\Delta x=x(t)-x(t-T) \\
\Delta y=y(t)-y(t-T)
\end{array}\right.
$$

where $T$ is the tooth period. As mentioned above, the static term of dynamic chip thickness $s_{t} \sin \left(\theta^{j}\right)$ is independent of the regenerative chatter. Thus, Eq. (13) can be simplified as follow when the regenerative chatter is concerned:

$$
h_{d}=\Delta x \sin \left(\varphi_{i}\right)+\Delta y \cos \left(\varphi_{i}\right)
$$

Therefore, the cutting forces along $x_{w}$ and $y_{w}$ can be finally presented as follow:

$$
\begin{aligned}
& {\left[\begin{array}{c}
F_{w x}(t) \\
F_{w y}(t)
\end{array}\right]=\frac{1}{2} K_{p t} \sum_{i=1}^{N} g\left(\theta_{i}\right) b\left(\theta^{i}\right)} \\
& {\left[\begin{array}{cc}
-K_{r}-\sin 2 \varphi_{i}+K_{r} \cos 2 \varphi_{i} & -1-K_{r} \sin 2 \varphi_{i}-\cos 2 \varphi_{i} \\
1-\cos 2 \varphi_{i}-K_{r} \sin 2 \varphi_{i} & -K_{r}-K_{r} \cos 2 \varphi_{i}+\sin 2 \varphi_{i}
\end{array}\right]\left[\begin{array}{l}
\Delta x(t) \\
\Delta y(t)
\end{array}\right]}
\end{aligned}
$$

where $K_{r}=K_{r c} / K_{t c} . F_{w z}$ and static components are ignored in this step. 


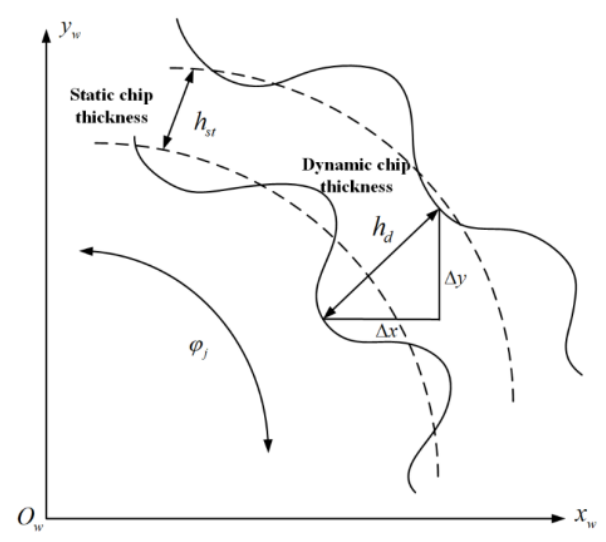

Figure 8. Dynamic chip thickness in helical milling process

In general, there are two approaches to solve the dynamics differential equations: frequency domain method and time domain method. The frequency domain method is an analytical method, which uses the existing mathematical model to obtain the required parameters for stability analysis, and then stability lobe diagrams can be drawn. The time domain method is realized by obtaining the ultimate cutting depth in the time domain and get the stability lobe. Comparing these two methods, the frequency domain method has a higher computational efficiency but relatively lower accuracy when the cutting forces are interrupted in this case. Therefore, the time domain method was selected in this paper. According to Li et al. [31] and Eq.(12), the motion equation for helical milling process can be expressed as:

$$
\begin{aligned}
& \left(\begin{array}{l}
(t) \\
(t)
\end{array}\right)+\left(\begin{array}{cc}
2 \zeta \omega_{n} & 0 \\
0 & 2 \zeta \omega_{n}
\end{array}\right)\left(\begin{array}{l}
(t) \\
m_{t}(t)
\end{array}\right)+\left(\begin{array}{cc}
\omega_{n}^{2}+\frac{w h_{x x}(t)}{m_{t}} & \frac{w h_{x y}(t)}{m_{t}} \\
\frac{w h_{y x}(t)}{m_{t}} & \omega_{n}^{2}+\frac{w h_{y y}(t)}{m_{t}}
\end{array}\right)\left(\begin{array}{l}
x(t) \\
y(t)
\end{array}\right) \\
& =\left(\begin{array}{ll}
\frac{w h_{x x}(t)}{m_{t}} & \frac{w h_{x y}(t)}{m_{t}} \\
\frac{w h_{y x}(t)}{m_{t}} & \frac{w h_{y y}(t)}{m_{t}}
\end{array}\right)\left(\begin{array}{l}
x(t-\tau) \\
y(t-\tau)
\end{array}\right)
\end{aligned}
$$

where $\xi$ is the relative damping ratio, $\omega_{n}$ is the angle natural frequency, $w$ is the cutting depth, $m_{t}$ is modal mass and $\tau$ is time delay and $h_{x x}(t), h_{x y}(t), h_{y x}(t)$ and $h_{y y}(t)$ are the specific cutting coefficient of 2- DOF, which can be obtained by following equation:

$$
\left\{\begin{array}{l}
h_{x x}(t)=\sum_{i=1}^{N} g\left(\phi_{i}(t)\right) \sin \left(\phi_{i}(t)\right)\left(K_{t c} \cos \left(\phi_{i}(t)\right)+K_{r c} \sin \left(\phi_{i}(t)\right)\right) \\
h_{x y}(t)=\sum_{i=1}^{N} g\left(\phi_{i}(t)\right) \cos \left(\phi_{i}(t)\right)\left(K_{t c} \sin \left(\phi_{i}(t)\right)+K_{r c} \sin \left(\phi_{i}(t)\right)\right) \\
h_{y x}(t)=\sum_{i=1}^{N} g\left(\phi_{i}(t)\right) \sin \left(\phi_{i}(t)\right)\left(-K_{t c} \cos \left(\phi_{i}(t)\right)+K_{r c} \sin \left(\phi_{i}(t)\right)\right) \\
h_{y y}(t)=\sum_{i=1}^{N} g\left(\phi_{i}(t)\right) \cos \left(\phi_{i}(t)\right)\left(K_{t c} \cos \left(\phi_{i}(t)\right)+K_{r c} \sin \left(\phi_{i}(t)\right)\right)
\end{array}\right.
$$

In the helical milling, the maximum axial engagement $a_{p}$, which is also called the axial feed 
per revolution, is taken to evaluate the cutting stability. Thus, $w$ is substituted by $a_{p}$ in Eq.(17). Similar to the ordinary milling process, the helical milling is also impacted by the time delay, which is caused by the combined motion of the peripheral milling, plunge milling and the feed rate of the cutting tool in helical milling. As the speed of revolution is much smaller than the spindle speed, and the axial cutting depth per revolution is quite small, the effect of feed rate and the helical angle on the delay can be ignored in helical milling. As shown in Fig.9, when the tool center is at $O_{1}$, the current cutting tooth is at point $\mathrm{B}$, and when the tool center moves to the point $O_{2}$, the previous cutting tooth is at point A. $\gamma^{\prime}-\gamma$ is the angle generated by the combined motion which lead to time delay. According to Ozturk et al.[13], the time delay between two successive teeth of helical milling can be expressed as follows:

$$
\tau=T \cdot\left[1-\cos \gamma \cdot\left(\frac{e}{R_{\mathrm{t}}}\right) \cdot\left(\frac{n_{c}}{n}\right)\right]
$$

where $T=60 / \mathrm{Nn}$ is the delay period for regular tool with uniform pitch angle. Since the revolution speed $n_{c}$ (see Fig. 1 (b)) is much smaller than the spindle speed $n$, we can assume $\tau \approx T=60 / N n$.

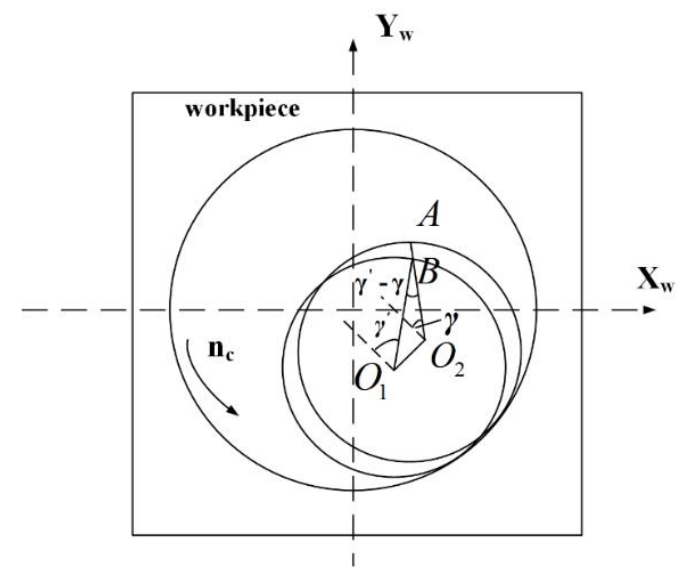

Figure 9. Time delay of helical milling

Therefore, by transforming Eq.(17) into space-state form and discretizing it with Complete Discretization Scheme with Euler's method (CDSEM) [31], we obtain

$$
\begin{aligned}
& \mathbf{u}_{\mathbf{k}+\mathbf{1}}=\left(\mathbf{I}-\frac{a}{\Delta t} \mathbf{A}_{\mathbf{k}}\right)^{-1}\left(\mathbf{I}+\left(1-\frac{a}{\Delta t}\right) \mathbf{A}_{\mathbf{k}}\right) \mathbf{u}_{\mathbf{k}} \\
& +\frac{a}{\Delta t}\left(\mathbf{I}-\frac{a}{\Delta t} \mathbf{A}_{\mathbf{k}}\right)^{-1} \mathbf{B}_{\mathbf{k}} \mathbf{u}_{\mathbf{k}-\mathbf{m}}+\left(1-\frac{a}{\Delta t}\right)\left(\mathbf{I}-\frac{a}{\Delta t} \mathbf{A}_{\mathbf{k}}\right)^{-1} \mathbf{B}_{\mathbf{k}} \mathbf{u}_{\mathbf{k}-\mathbf{m}+\mathbf{1}}
\end{aligned}
$$

where $\quad \mathbf{A}_{\mathbf{k}}=\left(\begin{array}{cccc}0 & 0 & 1 & 0 \\ 0 & 0 & 0 & 1 \\ -\left(\omega_{n}^{2}-\frac{w h_{x x, k}}{m_{t}}\right) & -\frac{w h_{x y, k}}{m_{t}} & -2 \zeta \omega_{n} & 0 \\ -\frac{w h_{y x, k}}{m_{t}} & -\left(\omega_{n}^{2}-\frac{w h_{x x, k}}{m_{t}}\right) & 0 & -2 \zeta \omega_{n}\end{array}\right)$ 
$\mathbf{B}_{\mathbf{k}}=\left(\begin{array}{cccc}0 & 0 & 0 & 0 \\ 0 & 0 & 0 & 0 \\ \frac{w h_{x x}, k}{m_{t}} & \frac{w h_{x y, k}}{m_{t}} & 0 & 0 \\ \frac{w h_{y x, k}}{m_{t}} & \frac{w h_{y y, k}}{m_{t}} & 0 & 0\end{array}\right), \mathbf{u}\left(\mathbf{t}_{\mathbf{k}}\right)=\left(\begin{array}{c}x_{k} \\ y_{k} \\ \&_{k} \\ \underset{k}{\&}\end{array}\right), a$ is the interpolation proportion parameter.

The coefficient matrix can be constructed as:

$$
\mathbf{C}_{\mathbf{k}}=\left(\begin{array}{ccccccccccc}
P_{k 11} & P_{k 12} & P_{k 13} & P_{k 14} & 0 & \mathrm{~L} & 0 & R_{k 1_{11}} & R_{k 1_{12}} & R_{k 2_{11}} & R_{k 2_{12}} \\
P_{k 11} & P_{k 22} & P_{k 23} & P_{k 24} & 0 & \mathrm{~L} & 0 & R_{k 1_{21}} & R_{k 1_{22}} & R_{k 2_{21}} & R_{k 2_{22}} \\
P_{k 31} & P_{k 32} & P_{k 33} & P_{k 34} & 0 & \mathrm{~L} & 0 & R_{k 1_{31}} & R_{k 1_{32}} & R_{k 2_{31}} & R_{k 2_{32}} \\
P_{k 41} & P_{k 42} & P_{k 43} & P_{k 44} & 0 & \mathrm{~L} & 0 & R_{k 1_{41}} & R_{k 1_{42}} & R_{k 2_{41}} & R_{k 2_{42}} \\
1 & 0 & 0 & 0 & 0 & \mathrm{~L} & 0 & 0 & 0 & 0 & 0 \\
0 & 1 & 0 & 0 & 0 & \mathrm{~L} & 0 & 0 & 0 & 0 & 0 \\
0 & 0 & 0 & 0 & 1 & \mathrm{~L} & 0 & 0 & 0 & 0 & 0 \\
\mathrm{M} & \mathrm{M} & \mathrm{M} & \mathrm{M} & \mathrm{M} & \mathrm{O} & \mathrm{M} & \mathrm{M} & \mathrm{M} & \mathrm{M} & \mathrm{M} \\
0 & 0 & 0 & 0 & 0 & \mathrm{~L} & 0 & 1 & 0 & 0 & 0 \\
0 & 0 & 0 & 0 & 0 & \mathrm{~L} & 0 & 0 & 1 & 0 & 0 \\
0 & 0 & 0 & 0 & 0 & \mathrm{~L} & 0 & 0 & 0 & 1 & 0
\end{array}\right)
$$

where

$$
\begin{aligned}
& P_{k}=\left(\mathbf{I}-\frac{a}{\Delta t} \mathbf{A}_{\mathbf{k}}\right)^{-1}\left(\mathbf{I}+\left(1-\frac{a}{\Delta t}\right) \mathbf{A}_{\mathbf{k}}\right) \\
& R_{k}=\frac{a}{\Delta t}\left(\mathbf{I}-\frac{a}{\Delta t} \mathbf{A}_{\mathbf{k}}\right)^{-1} \mathbf{B}_{\mathbf{k}}=\left(1-\frac{a}{\Delta t}\right)\left(\mathbf{I}-\frac{a}{\Delta t} \mathbf{A}_{\mathbf{k}}\right)^{-1} \mathbf{B}_{\mathbf{k}}
\end{aligned}
$$

Then, according to Eq.(21), the eigenvalues of transition matrix $\Phi$ can be constructed:

$$
\Phi=\mathrm{C}_{\mathrm{m}-1} \mathrm{C}_{\mathrm{m}-2} \ldots \mathrm{C}_{2} \mathrm{C}_{1} \mathrm{C}_{0}
$$

Therefore, in order to analyze the stability of helical milling, the relative damping ratio, angular natural frequency, and modal mass of robot-tool-workpiece system in $x_{w}$ and $y_{w}$ direction need to be determined first. According to Eq.(21) and Eq.(22), the eigenvalues of transition matrix can be calculated, and the cutting stability of helical milling can be predicted based on the Eq. (20) through CDSEM.

\section{Experimental results and discussion}

\subsection{Experimental set-up to identify of cutting force coefficients in PKM-based helical milling}

The experimental platform for TriMule helical milling and slot milling was built as shown in Fig. 10. The cutting force and subsequent dynamic experiments were all conducted in this platform. As shown in the figure, a Kistler three-direction dynamometer (9257A) with supporting charge 
amplifier (type 5070), and data acquisition system and Kistler software were utilized for the cutting force measurement.

The workpiece material used in this paper is titanium alloy Ti6Al4V, its physical and mechanical properties are shown in Table 2. The diameter of the helical milling holes in this paper is $19.05 \mathrm{~mm}$, and the carbide helical milling tool with $12 \mathrm{~mm}$ diameter was selected for the helical milling tests. The helical milling tool is shown in Fig.11, and details about cutting tool are listed in Table 3 .

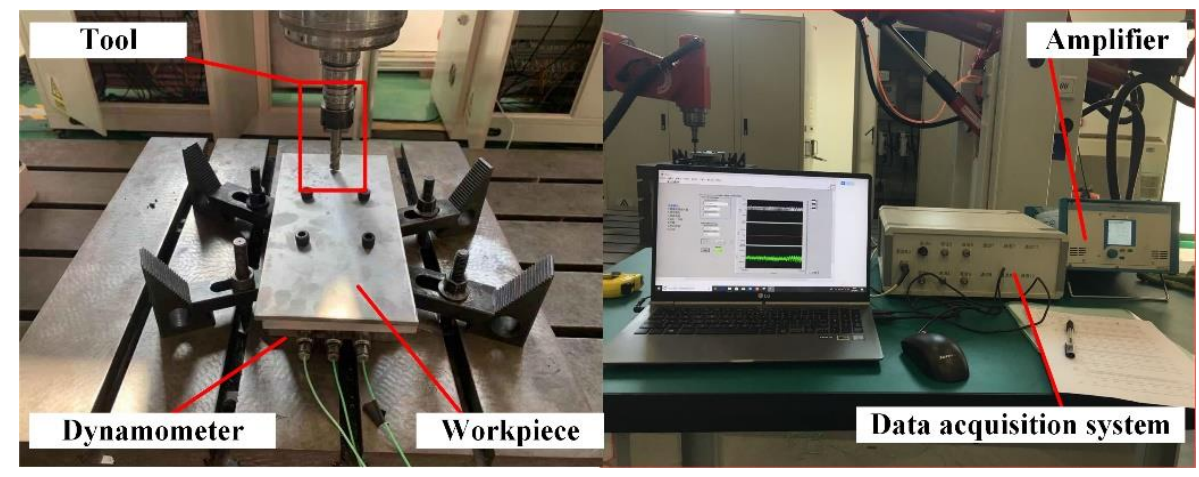

Figure.10 Experimental platform and machining tool for TriMule hybrid robot based helical milling
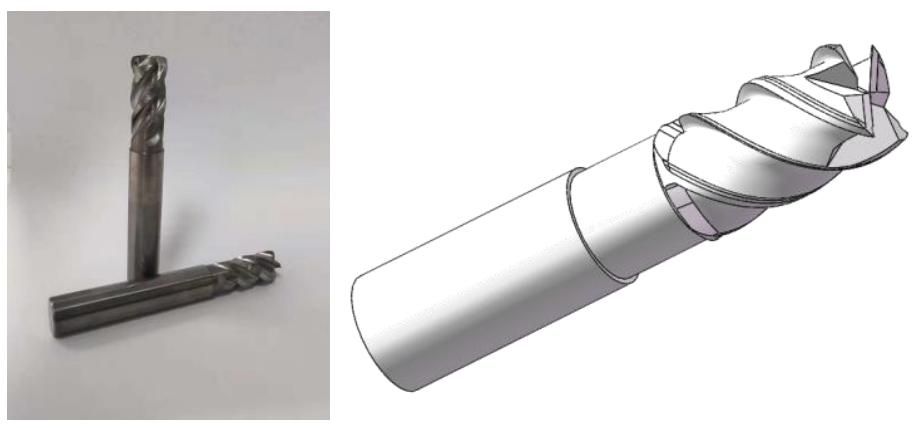

Figure.11 Helical milling tool and its 3D model

Table 2 Physical and mechanical properties of titanium alloys used in the experiment

\begin{tabular}{ccccccc}
\hline Properties & $\begin{array}{c}\text { Density } \\
\left(\mathrm{g} / \mathrm{cm}^{3}\right)\end{array}$ & $\begin{array}{c}\text { Tensile } \\
\text { strength } \\
(\mathrm{MPa})\end{array}$ & $\begin{array}{c}\text { Yield } \\
\text { strength } \\
(\mathrm{MPa})\end{array}$ & $\begin{array}{c}\text { Elastic } \\
\text { modulus } \\
(\mathrm{GPa})\end{array}$ & $\begin{array}{c}\text { Shear } \\
\text { modulus } \\
(\mathrm{MPa})\end{array}$ & $\begin{array}{c}\text { Poisson } \\
\text { ratio }\end{array}$ \\
\hline Value & 4.5 & 895 & 825 & 110 & 0.342 & 0.342 \\
\hline
\end{tabular}

Table 3 The geometric and property parameters of cutting tool used in the experiment

\begin{tabular}{ccccccc}
\hline Properties & Diameter & Rake angle & $\begin{array}{c}\text { Tool } \\
\text { clearance }\end{array}$ & $\begin{array}{c}\text { Helix } \\
\text { angel }\end{array}$ & $\begin{array}{c}\text { Number of } \\
\text { teeth }\end{array}$ & Materials \\
\hline Values & $12 \mathrm{~mm}$ & $8^{\circ}$ & $15^{\circ}$ & $40^{\circ}$ & 4 & K44 UF \\
\hline
\end{tabular}

In the experiment of cutting force coefficient identification, the tangential feed $s_{t}$ are selected as $0.02,0.03,0.04$, and $0.05 \mathrm{~mm} /$ tooth, the maximum axial engagement $a_{p}$ is $0.2 \mathrm{~mm} / \mathrm{rev}$ and the spindle speed $n$ is $2000 \mathrm{rpm}$. Based on the cutting force coefficients calibration method proposed in [33], the cutting coefficients of $K_{r c}, K_{t c}, K_{a c}, K_{r e}, K_{t e}$ and $K_{a e}$ were identified from a slot milling 
experiment, $K_{F a c}$ and $K_{F a e}$ were identified from a helical milling experiment. Finally, the cutting coefficients of titanium alloy helical milling can be obtained, shown in Table 4.

Table 4. Cutting coefficients of titanium alloy helical milling

\begin{tabular}{cccccccc}
\hline $\begin{array}{c}K_{r c} \\
\left(\mathrm{~N} / \mathrm{mm}^{2}\right)\end{array}$ & $\begin{array}{c}K_{t c} \\
\left(\mathrm{~N} / \mathrm{mm}^{2}\right)\end{array}$ & $\begin{array}{c}K_{a c} \\
\left(\mathrm{~N} / \mathrm{mm}^{2}\right)\end{array}$ & $\begin{array}{c}K_{r e} \\
(\mathrm{~N} / \mathrm{mm})\end{array}$ & $\begin{array}{c}K_{t e} \\
(\mathrm{~N} / \mathrm{mm})\end{array}$ & $\begin{array}{c}K_{a e} \\
(\mathrm{~N} / \mathrm{mm})\end{array}$ & $\begin{array}{c}K_{F a c} \\
\left(\mathrm{~N} / \mathrm{mm}^{2}\right)\end{array}$ & $\begin{array}{c}K_{F a e} \\
(\mathrm{~N} / \mathrm{mm})\end{array}$ \\
\hline 11036.5 & 10145 & 5000 & 100.03 & 591.92 & 214.32 & 243.47 & 33.072 \\
\hline
\end{tabular}

In order to verify the identified cutting force coefficients and proposed cutting force model, a validation experiment was conducted with a different cutting parameter ( $n=2000 \mathrm{rpm}$, $s_{t}=0.06 \mathrm{~mm} /$ tooth, and $a_{p}=0.2 \mathrm{~mm}$ ). As shown in Fig. 12, the predicted cutting forces agree well with the measured ones both in shape and magnitude. Therefore, the validity of the proposed cutting force prediction approach for helical milling is confirmed by the experiments. As shown in the figure, the average value of measured and simulated helical milling cutting force in $\mathrm{Z}$ direction are consistent with each other, however, the experimental measured results have significant periodic fluctuations, and the corresponding periodic is same with the rotation period of helical milling process (nc/60). Therefore, the reason might due to the periodic change of the robot axial stiffness and dynamic characteristics in the helix feed of hole-making process, which will result in the periodic fluctuation of the practical cutting force.

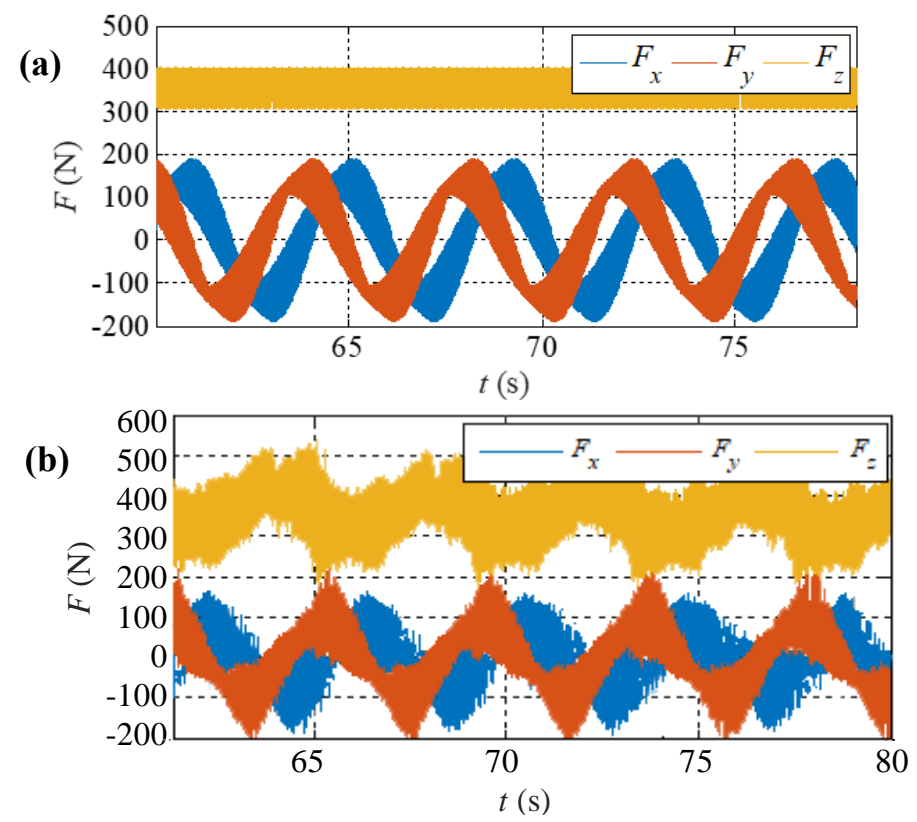

Figure 12. Cutting forces of titanium alloy helical milling in TriMule: (a) simulation result of cutting force (b) experimental measurement result of cutting force

\subsection{Identification of modal parameters of TriMule hybrid PKM}

In order to analyze the stability of helical milling, the modal parameters of the cutting system need to be determined first. Comparing with the $\mathrm{CNC}$ machine, the stiffness and damping ratio of TriMule are greatly influenced by working position. Thus, the variation of stiffness and damping ratio of TriMule with different working positions also need to be investigated carefully when considering the stiffness and damping ratio of the 2-DOF cutting dynamic model. In general, there 
are two main methods to get the parameter of a cutting system: finite element method (FEM) and modal experiment method.

However, for the FEM process of modal analysis, PKM modal analysis for different position is quite difficult due to the complexity of the structure and the limitations of current commercial finite element software. For the TriMule hybrid robot used in this paper, the mode order of each component of TriMule is around 400-1500 even after substantial modal simplification, which is still time consuming and always accompanied with unexpected simulation error. Therefore, in order to improve the calculation efficiency and reduce the simulation errors of modal parameters, the experimental method was conducted in this paper. The modal experiment for the whole system of TriMule-tool shank-tool was carried out by means of hammer impact, and several representatives positions were selected in the experiment.

The experimental platform of TriMule helical milling modal testing was presented in Fig.13. The B\&K impact hammer and PCB acceleration sensor were used to shock excitation and pick up the generated vibration signals. The input and output signals are processed through the data collection system of LMS, and the modal data processing is imported into the analysis software. In this paper, the modal test is carried out by single point impact and single point vibration signal pickup method. As TriMule is a complex high-order system, multiple vibration pickup points were arranged, as shown in Fig. 14. At the same time, the impact hammer strikes along different directions of each impact point. In order to reduce the random measurement error, the vibration measurement test for every pickup point repeated five times.

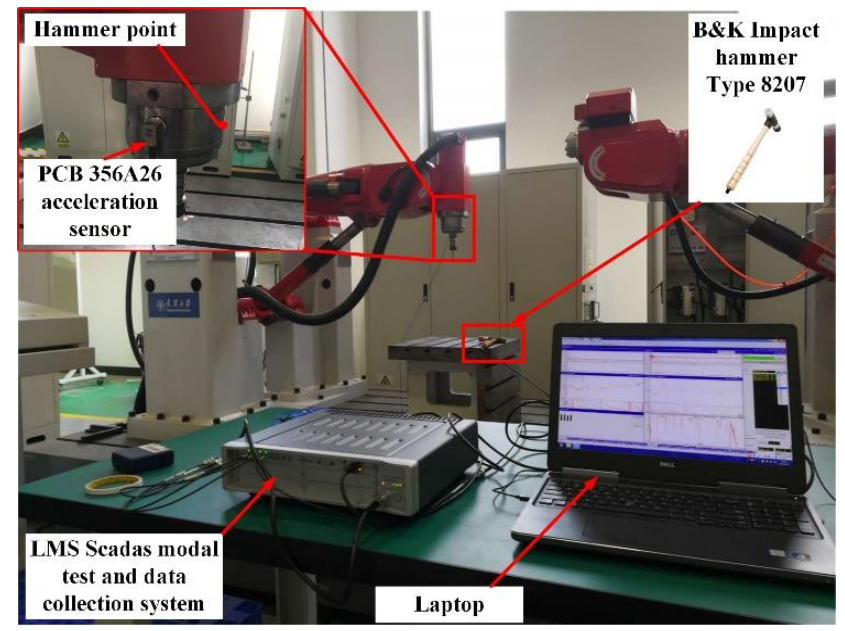

Figure 13. Experimental platform of TriMule robot based helical milling modal testing

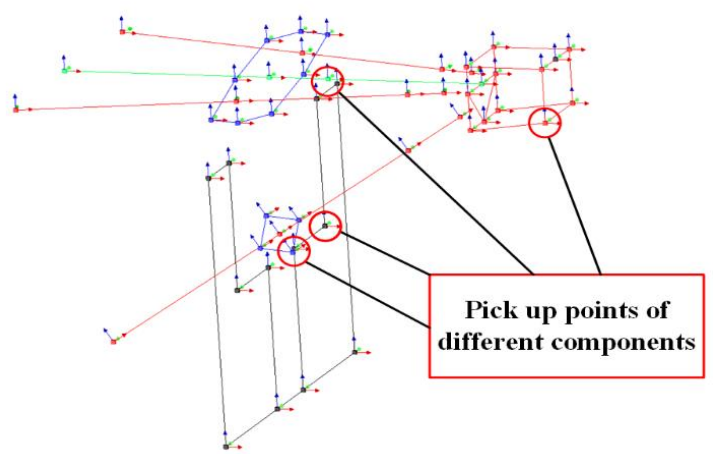

Figure 14. Arrangement of vibration pickup points on TriMule robot modal testing 
As shown in Fig.15, coordinate system $O_{m}-x_{m} y_{m} z_{m}$ is established to describe the position of the TriMule when conducting modal experiments. In order to analyze the influence of robot position on the cutting stability, seven representative positions with larger robot end stiffness (simulation results in Fig. 4) were selected in the workspace, and the corresponding coordinates are shown in Table 5.

Table 5. Coordinates value of representative positions in the workspace of TriMule

\begin{tabular}{cccc}
\hline Number of positions & $x_{m}(\mathrm{~mm})$ & $y_{m}(\mathrm{~mm})$ & $z_{m}(\mathrm{~mm})$ \\
\hline 1 & 0 & 0 & 0 \\
2 & 0 & 0 & -320 \\
3 & 0 & 200 & -320 \\
4 & -200 & 0 & -320 \\
5 & -400 & 0 & -320 \\
6 & -200 & 0 & 50 \\
7 & 0 & 200 & 0 \\
\hline
\end{tabular}

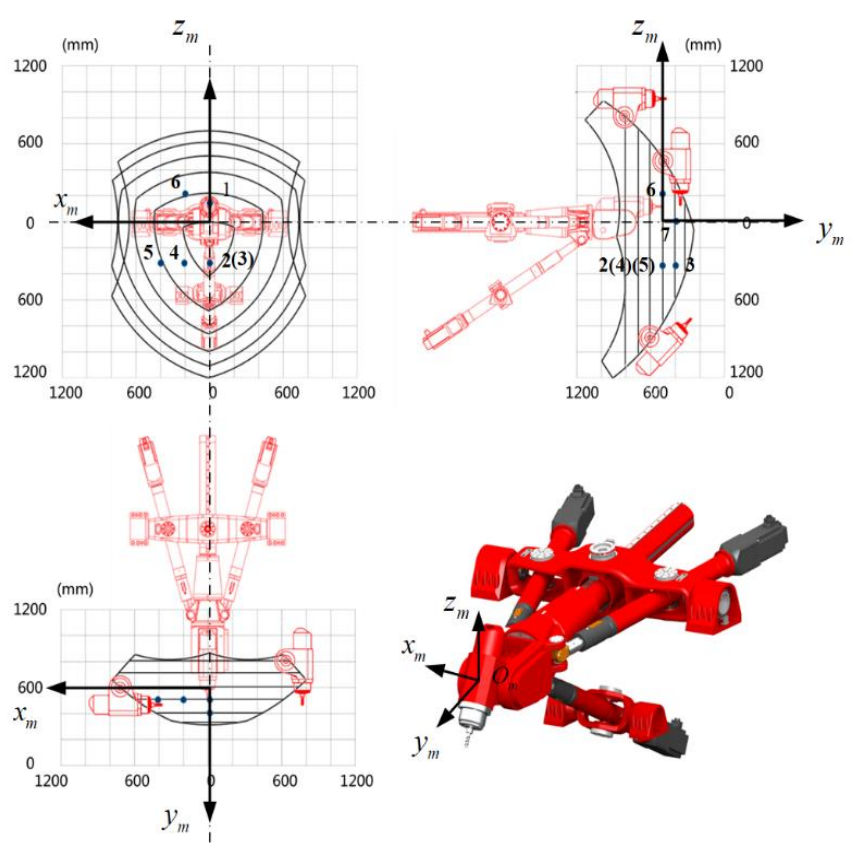

Figure 15. Seven representative positions in the workspace of TriMule

Firstly, the modal test pickup point model of seven representative positions were established to measure the frequency response function (FRF) of TriMule, and then, the natural frequency and modal parameters of the whole system can be identified. As TriMule is used for helical milling of titanium alloy in this study, only the first four modes are considered in the mode identification. The identified modes and natural frequencies are used to reconstruct the frequency response function, which has compared with the original frequency response function obtained in the experiment (shown in Fig. 16). It can be found that the mode identification error is about 3\%-5\% for those close to the impact point, while the error is relatively larger for those far away from the excitation point. This indicates that the remote end of TriMule has a good shock-proof effect. As shown in Fig. 16, taking two pickup points on the limb of UPS for position 1 as example, it can be seen that the error between the reconstructed FRF based on the selected natural frequency and that obtained by modal 
test is within an acceptable range.

Compared with the least squares time domain method, the PolyMAX method is more suitable for complex systems with large damping such as TriMule. Therefore, the PolyMAX method, which is supported by LMS modal analysis software, was used for modal parameter identification in this paper. Based on the above method, the modal parameters of the seven representative positions were obtained by the maximum element normalization method, and the modal parameters of the position 1 are given in Table 6 as an example. According to the FRF results of the whole system, the cross coupling between the $x_{m}$ and $z_{m}$ is negligible as the amplitude is far more less than the others.

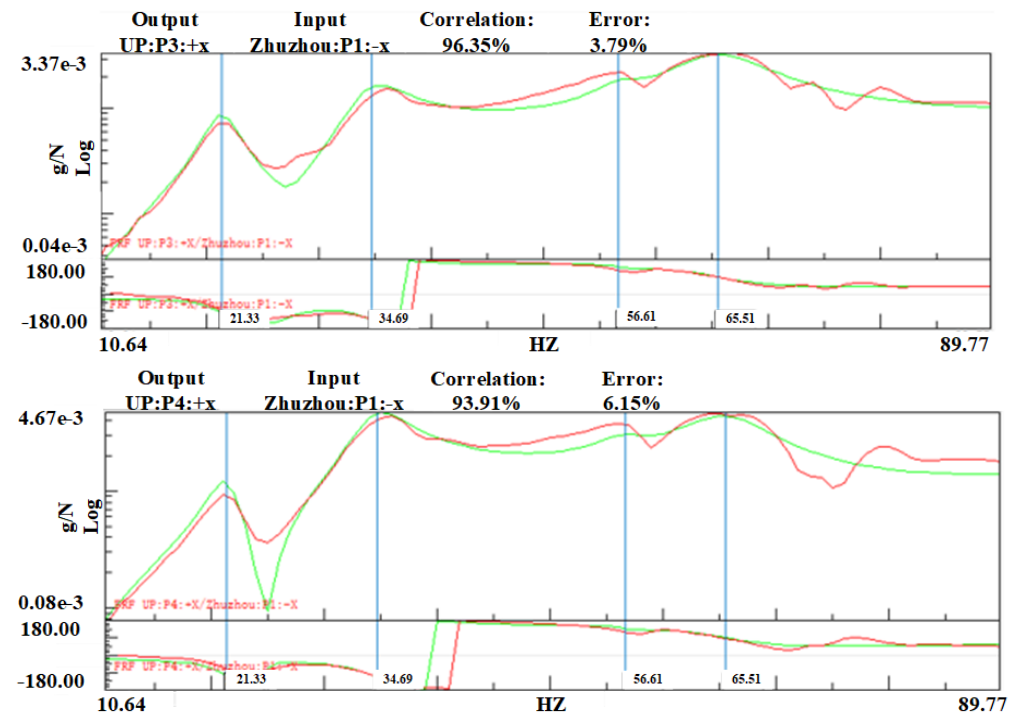

Figure 16. Schematic diagram of modal reconstruction of pickup point for position 1: The green curve is the reconstructed frequency response function, and the red curve is the measured frequency response function.

Table 6. The modal parameters of TriMule in position 1

\begin{tabular}{cccccc}
\hline Directions & $\begin{array}{c}\text { Number of } \\
\text { modes }\end{array}$ & $\begin{array}{c}\text { Natural } \\
\text { frequency }(\mathrm{Hz})\end{array}$ & $\begin{array}{c}\text { Damping } \\
\text { ratio }(\%)\end{array}$ & $\begin{array}{c}\text { Modal stiffness } \\
(\mathrm{N} / \mathrm{m})\end{array}$ & $\begin{array}{c}\text { Modal mass } \\
(\mathrm{kg})\end{array}$ \\
\hline \multirow{3}{*}{$x_{m}$} & 1 & 21.3257 & 6.08951 & $7.25548 \mathrm{e}+06$ & 402.61 \\
& 2 & 34.6937 & 7.07726 & $4.05902 \mathrm{e}+06$ & 84.9923 \\
& 3 & 56.6075 & 3.5692 & $4.18385 \mathrm{e}+06$ & 33.0305 \\
& 4 & 65.5141 & 6.33944 & $2.21663 \mathrm{e}+06$ & 13.0291 \\
\hline \multirow{3}{*}{$z_{m}$} & 1 & 31.4277 & 6.71896 & $3.1541 \mathrm{e}+08$ & 8052.43 \\
& 2 & 35.0952 & 4.76042 & $7.06418 \mathrm{e}+07$ & 1449.51 \\
& 3 & 54.7344 & 4.99933 & $4.71786 \mathrm{e}+07$ & 397.904 \\
& 4 & 67.2582 & 3.79608 & $1.46188 \mathrm{e}+07$ & 81.7399 \\
\hline
\end{tabular}

\subsection{Positional dependent stability lobe of TriMule hybrid robot based helical milling}

With the obtained modal parameters of TriMule under different positions, the stability lobe diagram of TriMule robot based helical milling of titanium alloy can be drawn according to the method mentioned in Section 3, and the line chart of the limit axial cutting depth per revolution for different positions was also obtained, as shown in Fig. 17. The line chart presented the stability limits of different positions with the spindle speeds chosen from 500rpm to 2500rpm for the seven 
(a)

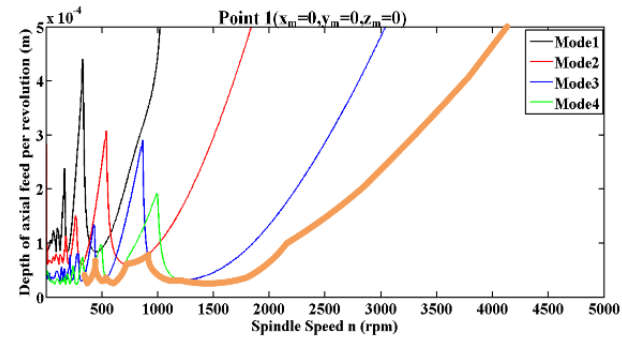

(c)

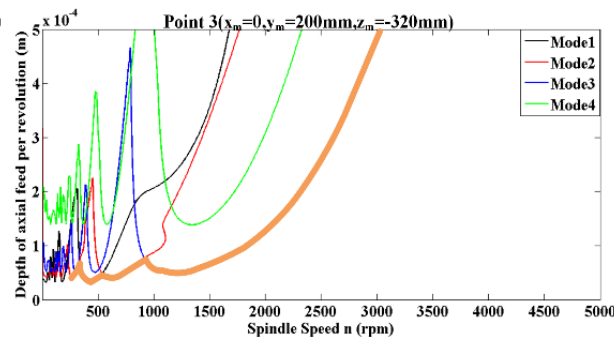

(e)

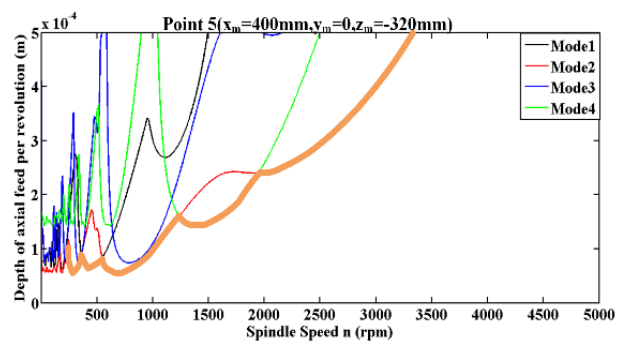

(g)

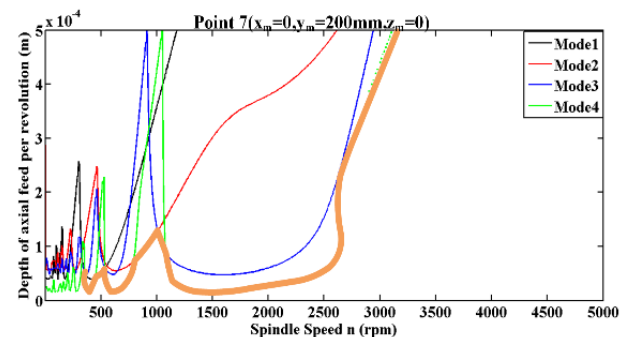

(b)

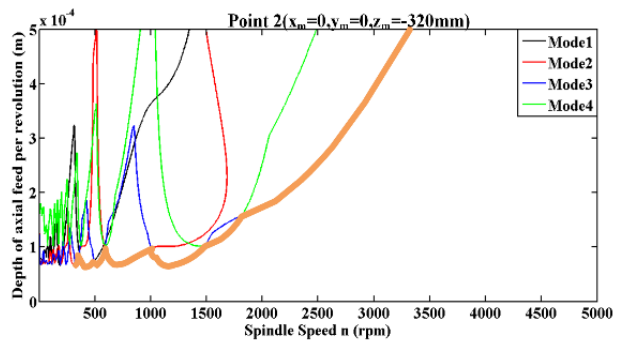

(d)

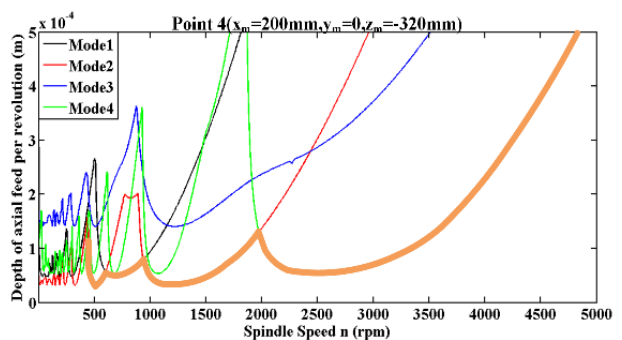

(f)

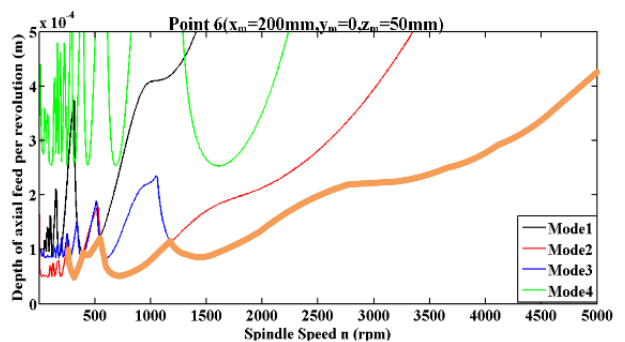

(h)

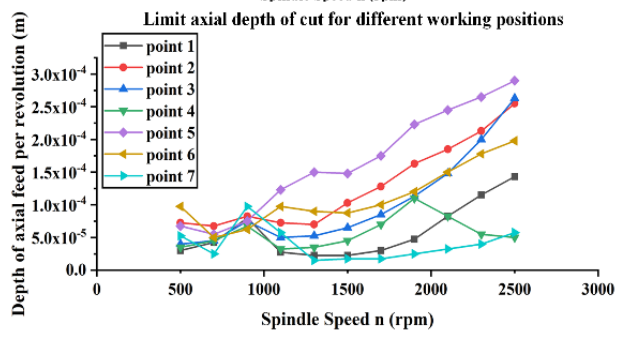

Figure. 17 Predicted results of TriMule titanium alloy helical milling stability, (a)-(g) Stability lobe diagram for seven representative working positions: the orange bold solid line is the stability lobe under the influence of first 4 modes of TriMule, and (h) Comparison of limit axial depth of cut for different working positions

representative machining positions with the step of 200rpm. According to the structural characteristics of TriMule, the axial immersion ratio was chosen to be 1 in the stability lobe diagram drawing process. The natural modes of vibration are considered to be uncoupled, thus, the final stability lobe of TriMule is the minimum of the graphs obtained for each mode [34], which is marked by the orange solid line in the Fig.17. As shown in the figure, the helical milling stability lobe diagrams for the seven representative positions are quite different, and it can be found that the hybrid PKM position has a great influence on the corresponding limit stable axial depth of cut. By comparing the stability lobes diagram of position 1 (Fig. 17 (a)) and position 2 (Fig.17 (b)), it can be found that the helical milling stability limits increase with increasing of $y_{m}$ when $x_{m}$ and $z_{m}$ remains zero. However, it is also found that the overall cutting stability limits decrease when the $z_{m}$ increases by comparing the stability lobe diagram of position 2 (Fig.17(b)),3 (Fig.17(c))and position 1 (Fig.17(a)),7(Fig.17(g)).As for the influence of $x_{m}$ coordinate on the overall cutting stability, from comparing the stability lobe of position 2,4 and 5 , it can be seen that the stability limits show a 
trend of rising and then falling. Based on the requirements of both quality and efficiency in the titanium helical milling hole-making process, the cutting stability limit corresponding to spindle speed between $1000 \mathrm{rpm}$ to $2500 \mathrm{rpm}$ was investigated. As shown in Fig. 17(h), it can be seen that the cutting stability limits are almost the same in different positions when the spindle speed is less than 1000rpm, and when the spindle speed exceeds $1000 \mathrm{rpm}$, the helical milling stability limits show great difference between different machining position for the TriMule robot. For example, the position 7 ( $\left.x_{m}=0, y_{m}=0, z_{m}=200 \mathrm{~mm}\right)$ has the smallest stability limits when the spindle speed is more than 1500rpm whereas it has the greatest stability limits when the spindle speed is around 1000rpm comparing with other selected positions.

In addition, the main mode orders that affect the cutting stability limits for the different PKM machining position are compared in Fig. 18. As it can be seen, the main influence mode order on cutting stability increases with the increasing of spindle speed except for position 5. Meanwhile, the helical milling stability is only determined by the 2nd,3rd and 4th order modes when the spindle speed is higher than $1000 \mathrm{rpm}$. This indicates that the cutting stability for TriMule based titanium alloy helical milling can be further improved by optimizing the 2nd,3rd and 4th modal parameters.

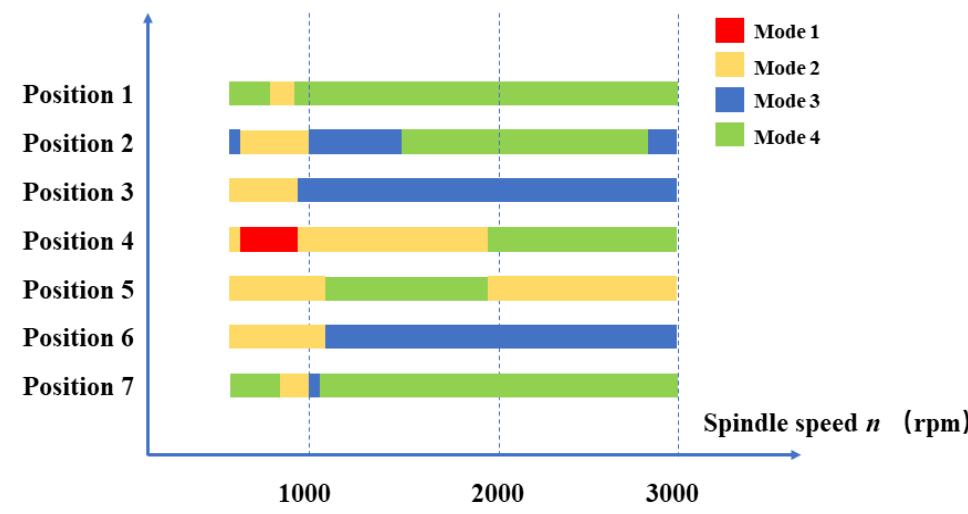

Figure 18. Analysis of Mode orders that affect the cutting stability limits for the different PKM machining position

\subsection{Verification of TriMule robot based helical milling stability model}

In this paper, a diameter of $19.05 \mathrm{~mm}$ was helical milled by a cutting tool with a diameter of $12 \mathrm{~mm}$, and the cutting tests were conducted at a fixed tangential feed per tooth $\left(s_{i}=0.02 \mathrm{~mm}\right)$ to verify the predicted stability lobe diagram, in which the spindle speeds were selected from 1000rpm to $2500 \mathrm{rpm}$ with a step size of $500 \mathrm{rpm}$. For each of these spindle speeds, the initial depth of axial feed per revolution was set as $0.05 \mathrm{~mm}$ and increased with a step of $0.05 \mathrm{~mm}$ until the chatter occurs. In the experimental verification process, the cutting force signal both in the $x_{w}$ and $y_{w}$ direction were measured and the chatter in the helical milling process was distinguished using the fast Fourier Transform (FFT) approach. The typical cutting force signal FFT results for both stable and unstable TriMule robot based helical milling were presented in the Fig. 19. The high frequency components which are different from tooth pass frequency and corresponding multiplier frequency can be observed in the case of unstable helical milling Fourier spectra. Based on the above verification method, the comparison of predicted stability lobe diagram with three representative experimental results for TriMule robot based helical milling were shown in Fig.20. It can be concluded that the 
predicted and experimental boundaries of TriMule robot based helical milling agree well for different machining positions.

(a)

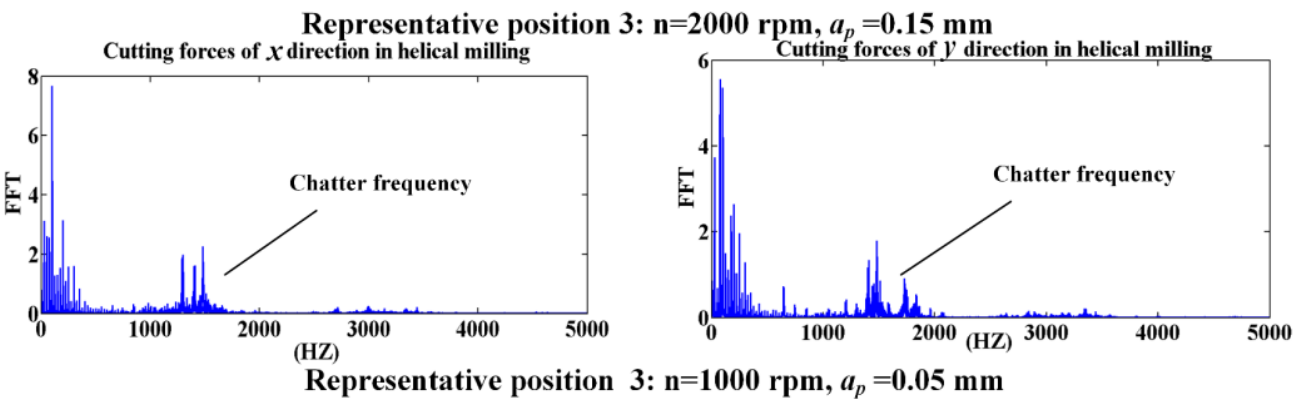

(b)
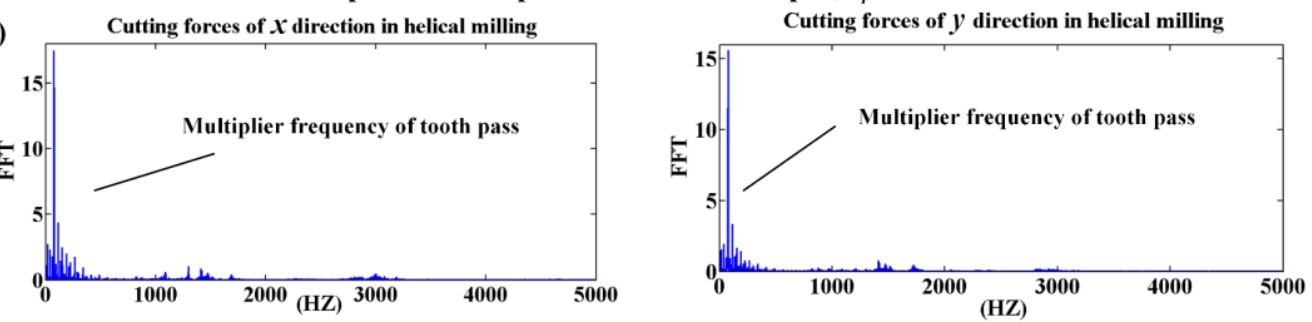

Figure. 19 Comparing of cutting force signal FFT results for (a) chatter occur and (b) stable cutting conditions
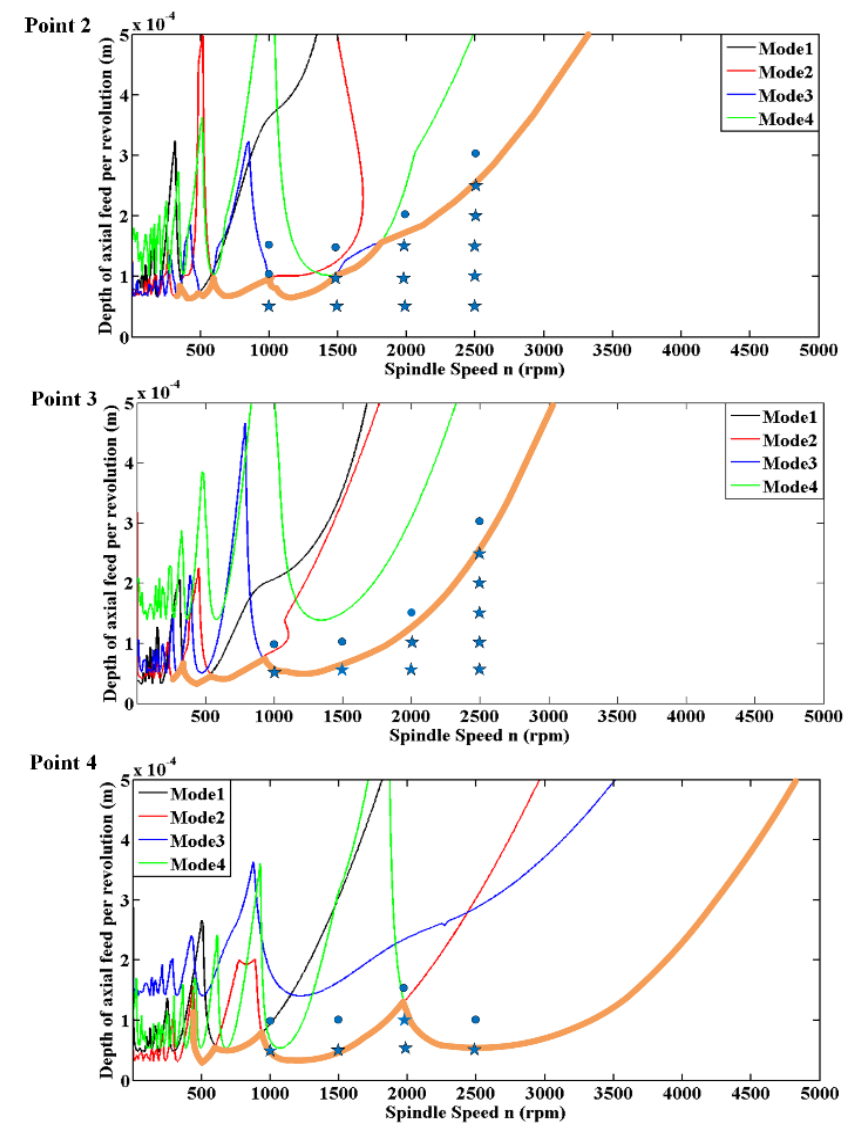

Figure 20. Stability comparison between prediction and experiment results for TriMule based helical milling: “ $\star$ ”and “॰” represented stable positions and unstable positions respectively. 
Additionally, the influence of helical milling stability on the machined hole surface quality was also investigated. In this paper, the roughness of helical milling machined holes at different hybrid PKM machining positions were measured using Talyor Hobson profilometer. In order to reduce the random measurement errors, the roughness of each test was measured 4 times to obtain the mean value of surface roughness $\mathrm{Ra}$. The average value of machined hole surface roughness of representative positions in stable and unstable helical milling conditions were compared in the Fig. 21. It can be found that the surface roughness corresponding to the unstable helical milling are 0.1$0.2 \mu \mathrm{m}$ larger than that in the stable condition. Besides, it also can be seen from the figure that the machining position is also an important factor affecting the PKM-based helical milling surface roughness due to the variation of cutting stability with the machining position. To sum up, it can be seen that, unlike traditional machine tools, the cutting stability of hybrid PKM have a strong correlation with their working positions.

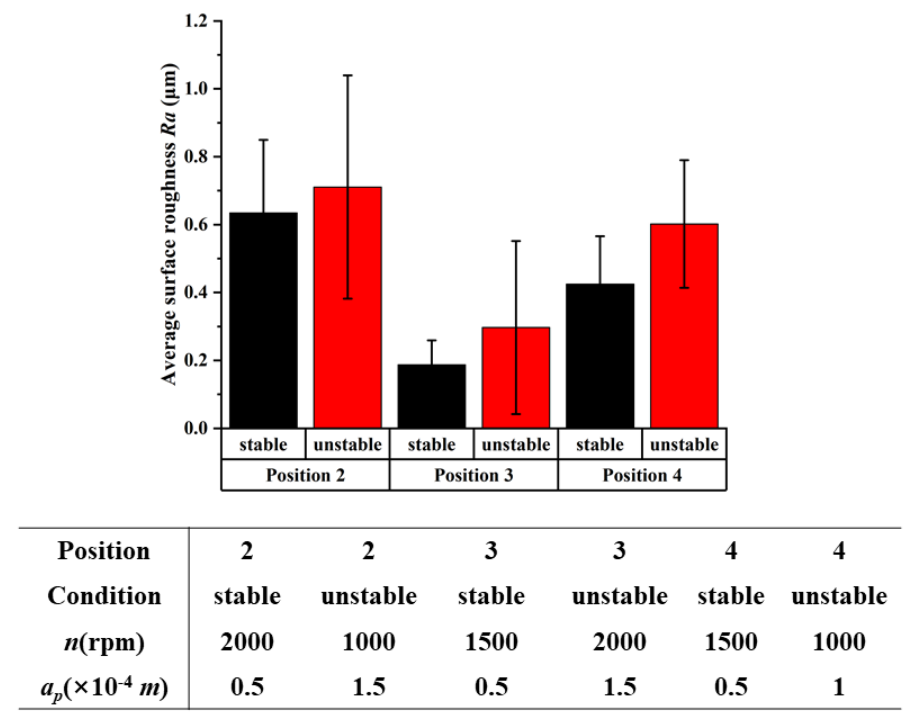

Figure 21. Surface roughness $R_{a}$ of representative positions in stable and unstable helical milling conditions

\section{Conclusions}

Combing the advantages of helical milling hole-making operation and PKM, the PKM based helical milling operation is an alternative solution to improve the quality and efficiency of aircraft assembly. In this paper, the cutting force model for the TriMule based titanium alloy helical milling is proposed, and the corresponding cutting force coefficients for side cutting edge and front cutting are identified based on the slot and helical milling experiments respectively. On the basis, the dynamic model of PKM-based helical milling is presented and the chatter stability diagram at the seven representative machining positions are obtained based on the CDSEM approach. Experimental results show that predicted and experimental boundaries of TriMule robot based helical milling agree well for different machining positions.

Based on the predicted stability lobe diagrams, it can be found that the hybrid PKM machining position has a great influence on the corresponding stable limit axial depth of cut in the helical milling operation. Meanwhile, it was indicated that the spindle speed is an important factor affecting the helical milling stability difference at different machining positions. For the seven selected 
machining positions, it can be seen that the cutting stability limits are almost the same when the spindle speed is less than 1000rpm, and when the spindle speed exceeds $1000 \mathrm{rpm}$, the helical milling stable limits show great difference between different machining positions for TriMule robot. The influence of PKM-based helical milling stability on the machined hole surface quality was also investigated. It was presented that the unstable cutting condition always accompanied by a larger surface roughness, and the machining position is also an important factor affecting the PKM-based helical milling surface roughness.

\section{Acknowledgements}

This work was supported by National key research and development program of China (grant number: 2017YFE0111300) and National Nature Science Foundation of China (grant numbers: 51705358, and 51775373), and EU H2020-RISE-ECSASDPE (grant number: 734272).

\section{References}

1. Pereira RBD, Brandão LC, de Paiva AP, Ferreira JR, Davim JP (2017) A review of helical milling process. International Journal of Machine Tools and Manufacture 120:27-48. doi:10.1016/j.ijmachtools.2017.05.002

2. Ramulu M, Branson T, Kim D (2001) A study on the drilling of composite and titanium stacks. Composite structures 54 (1):67-77

3. Eguti CCA, Trabasso LG (2014) Design of a robotic orbital driller for assembling aircraft structures. Mechatronics 24 (5):533-545. doi:10.1016/j.mechatronics.2014.06.007

4. Ji C, Li Y, Qin X, Zhao Q, Sun D, Jin Y (2015) 3D FEM simulation of helical milling hole process for titanium alloy Ti-6Al-4V. The International Journal of Advanced Manufacturing Technology 81 (9-12):1733-1742. doi:10.1007/s00170-015-7323-8

5. Kim D, Sturtevant C, Ramulu M (2013) Usage of PCD tool in drilling of titanium/graphite hybrid composite laminate. International Journal of Machining and Machinability of Materials 13 (23):276-288

6. Zitoune R, El Mansori M, Krishnaraj V (2013) Tribo-functional design of double cone drill implications in tool wear during drilling of copper mesh/CFRP/woven ply. Wear 302 (1-2):15601567. doi:10.1016/j.wear.2013.01.046

7. Liu C, Wang G, Dargusch MS (2012) Modelling, simulation and experimental investigation of cutting forces during helical milling operations. The International Journal of Advanced Manufacturing Technology 63 (9-12):839-850. doi:10.1007/s00170-012-3951-4

8. Liu J, Chen G, Ji C, Qin X, Li H, Ren C (2014) An investigation of workpiece temperature variation of helical milling for carbon fiber reinforced plastics (CFRP). International Journal of Machine Tools and Manufacture 86:89-103. doi:10.1016/j.ijmachtools.2014.06.008

9. Wang H, Qin X, Li H, Tan Y (2016) A comparative study on helical milling of CFRP/Ti stacks and its individual layers. The International Journal of Advanced Manufacturing Technology 86 (5-8):1973-1983. doi:10.1007/s00170-015-8296-3

10. Wang H, Qin X, Ren C, Wang Q (2011) Prediction of cutting forces in helical milling process. The International Journal of Advanced Manufacturing Technology 58 (9-12):849-859. doi:10.1007/s00170-011-3435-y

11. Li Z, Liu Q, Ming X, Wang X, Dong Y (2014) Cutting force prediction and analytical solution 
of regenerative chatter stability for helical milling operation. The International Journal of Advanced Manufacturing Technology 73 (1-4):433-442. doi:10.1007/s00170-014-5793-8

12. Liu C, Wang G, Dargusch MS (2014) Mechanics and Dynamics of Helical Milling Operations. Strojniški vestnik-Journal of Mechanical Engineering, 60(11), 716-724. doi: 10.5545/svjme.2013.1588.

13. Ozturk OM, Kilic ZM, Altintas Y (2018) Mechanics and dynamics of orbital drilling operations. International Journal of Machine Tools and Manufacture 129:37-47. doi:10.1016/j.ijmachtools.2018.03.001

14. Shan Y-c, He N, Li L, Zhao W, Yang Y-f (2013) Vector modeling of robotic helical milling hole movement and theoretical analysis on roughness of hole surface. Journal of Central South University 20 (7):1818-1824. doi:10.1007/s11771-013-1678-5

15. Chen QL, Chen XM, Duan ZH, Cun WY (2014) Research on Helical Milling Specialized Tool Based on Chip-Splitting Mechanism. Advanced Materials Research 1061-1062:497-506. doi:10.4028/www.scientific.net/AMR.1061-1062.497

16. Cordes M, Hintze W, Altintas Y (2019) Chatter stability in robotic milling. Robotics and Computer-Integrated Manufacturing 55:11-18. doi:10.1016/j.rcim.2018.07.004

17. Huynh HN, Assadi H, Rivière-Lorphèvre E, Verlinden O, Ahmadi K (2020) Modelling the dynamics of industrial robots for milling operations. Robotics and Computer-Integrated Manufacturing 61. doi:10.1016/j.rcim.2019.101852

18. Mousavi S, Gagnol V, Bouzgarrou BC, Ray P (2018) Stability optimization in robotic milling through the control of functional redundancies. Robotics and Computer-Integrated Manufacturing 50:181-192. doi:10.1016/j.rcim.2017.09.004

19. DeVlieg R, Sitton K, Feikert E, Inman J (2002) ONCE (one-sided cell end effector) robotic drilling system. SAE Technical Paper,

20. Tsai L-W (1999) The mechanics of Serial and Parallel manipulators. Robot Analysis, John Wiley \& Sons, Inc

21. Weck M, Staimer D (2002) Parallel Kinematic Machine Tools - Current State and Future Potentials. CIRP Annals 51 (2):671-683. doi:10.1016/s0007-8506(07)61706-5

22. Zhang D (2010) Parallel robotic machine tools. Springer, Oshawa

23. Möller C, Schmidt HC, Koch P, Böhlmann C, Kothe S-M, Wollnack J, Hintze W (2017) Machining of large scaled CFRP-Parts with mobile CNC-based robotic system in aerospace industry. Procedia manufacturing 14:17-29. doi:10.1016/j.promfg.2017.11.003.

24. Najafi A, Movahhedy MR, Zohoor H, Alasty A(2016) Dynamic stability of a Hexaglide machine tool for milling processes. The International Journal of Advanced Manufacturing Technology 86 (5-8):1753-1762. doi:10.1007/s00170-015-8331-4

25. Pedrammehr S, Mahboubkhah M, Khani N (2012) A study on vibration of Stewart platformbased machine tool table. The International Journal of Advanced Manufacturing Technology 65 (5-8):991-1007. doi:10.1007/s00170-012-4234-9

26. Law M, Ihlenfeldt S, Wabner M, Altintas Y, Neugebauer R (2013) Position-dependent dynamics and stability of serial-parallel kinematic machines. CIRP Annals 62 (1):375-378. doi:10.1016/j.cirp.2013.03.134

27. Tunc LT, Shaw J (2016) Investigation of the effects of Stewart platform-type industrial robot on stability of robotic milling. The International Journal of Advanced Manufacturing Technology 87 (1-4):189-199. doi:10.1007/s00170-016-8420-z 
28. Huang T, Dong C, Liu H, Qin X, Mei J, Liu Q, Wang M (2018) Five-degree-of-freedom hybrid robot with rotational supports. US Patent disclosure 9943967

29. Campa FJ, Lopez de Lacalle LN, Lamikiz A, Bilbao E, Calleja A, Penafiel J (2009) Tool deflection on peripheral milling. In: The annals of Dunarea de Jos University of Galati, Fascicle $\mathrm{V}$,technologies in machine building

30. Budak E, Altintas, Y (1998) Analytical Prediction of Chatter Stability in Milling-Part I: General Formulation. Journal of Dynamic Systems, Measurement, and Control 120 (1):22-30. doi:10.1115/1.2801317

31. Li Z, Liu Q, Ming X, Wang X, Dong Y (2014) Cutting force prediction and analytical solution of regenerative chatter stability for helical milling operation. The International Journal of Advanced Manufacturing Technology 73 (1-4):433-442. doi:10.1007/s00170-014-5793-8

32. Li M, Zhang G, Huang Y (2012) Complete discretization scheme for milling stability prediction. Nonlinear Dynamics 71 (1-2):187-199. doi:10.1007/s11071-012-0651-4

33. Shang S, Qin XD, Li JH, Li SP, Li H, Huang T, Jin Y, Sun D (2017) Modelling of cutting forces and researching calibration method in helical milling. The International Journal of Advanced Manufacturing Technology 94 (5-8):2949-2960. doi:10.1007/s00170-017-1117-0

34. Seguy S, Dessein G, Arnaud L (2008) Surface roughness variation of thin wall milling, related to modal interactions. International Journal of Machine Tools and Manufacture 48 (3-4):261274. doi:10.1016/j.ijmachtools.2007.09.005 